\title{
Non-exclusive dynamic contracts, competition, and the limits of insurance
}

\author{
Laurence Ales ${ }^{\mathrm{a}, *}$, Pricila Maziero ${ }^{\mathrm{b}, *}$ \\ a Tepper School of Business, Carnegie Mellon University, United States \\ ${ }^{\mathrm{b}}$ The Wharton School, University of Pennsylvania, United States
}

Received 13 March 2014; final version received 18 June 2016; accepted 18 September 2016

Available online 28 September 2016

\begin{abstract}
We study how the presence of non-exclusive contracts limits the amount of insurance provided in a decentralized economy. We consider a dynamic Mirrleesian economy in which agents are privately informed about idiosyncratic labor productivity shocks. Agents sign privately observable insurance contracts with multiple firms (i.e., they are non-exclusive). Contracts specify both labor and savings requirements. Firms have no restriction on the contracts they can offer and interact strategically. In equilibrium, contrary to the case with exclusive contracts, a standard Euler equation holds, and the marginal rate of substitution between consumption and leisure is equated to the worker's marginal productivity. Also, each agent receives zero net present value of transfers. These conditions imply the equilibrium allocation is equivalent to a standard incomplete markets model. To sustain this equilibrium, more than one firm must be active and must also offer latent contracts to deter deviations to more profitable contingent contracts. In this environment, the non-observability of contracts removes the possibility of additional insurance beyond self-insurance.
\end{abstract}

(c) 2016 Elsevier Inc. All rights reserved.

JEL classification: D80; D82; D91; E20; H20

\footnotetext{
We are grateful to Larry Jones, Patrick Kehoe, and V.V. Chari for their continuous help and support. We thank Arpad Abraham, Mark Aguiar, Andy Atkeson, Ricardo Avelino, Kim-Sau Chung, Mike Golosov, Roozbeh Hosseini, Narayana Kocherlakota, Ellen McGrattan, Lee Ohanian, Nicola Pavoni, Fabrizio Perri, Christopher Sleet, Aleh Tsyvinski, Gianluca Violante, Pierre Yared, and Sevin Yeltekin for comments and suggestions, Marianne Holohan for editorial assistance. Remaining mistakes are ours.

* Corresponding authors.

E-mail addresses: ales@cmu.edu (L. Ales), maziero@wharton.upenn.edu (P. Maziero).
} 
Keywords: Optimal dynamic social insurance; Non-exclusive contracts; Incomplete markets; Optimal taxation; Private information

\section{Introduction}

What type of contractual arrangements are available to workers in a decentralized economy when firms compete for the provision of social insurance? In this paper, we study how, in a decentralized economy, the presence of non-exclusive contracts endogenously limits the contracts offered, and hence, the amount of insurance. We find that competition and non-exclusivity of insurance contracts significantly reduce the amount of insurance provided: the equilibrium allocation in our environment is equivalent to a self-insurance economy, and only linear contracts are offered.

Multiple credit and labor relations are an important aspect of everyday life. Survey data shows that individuals and households receive insurance against idiosyncratic risk from a multitude of sources: publicly provided insurance (unemployment, Medicare, Medicaid, disability, food stamps, progressive income taxation); privately provided insurance (employer, between and within family transfers $)^{1}$; financial instruments in credit markets; and housing and other large durable goods. The same consideration is true for labor relationships. Paxson and Sicherman (1994) look at the number of concurrent labor relationships held by survey respondents of the Panel Study of Income Dynamics (PSID) between 1977 and 1990 and the Current Population Survey (CPS) of 1991. They find that for any given year, $20 \%$ of working males held at least a second job, and during their working life, there is at least a $50 \%$ probability of holding a second job. However, monitoring all the transactions an agent might engage in with other firms is very costly for an individual firm, especially if these relationships include activities in the informal labor market, private savings, and the ability to transfer leisure into consumption through either home production or shopping time (see Aguiar and Hurst, 2005). Motivated by these considerations, the key friction addressed in this paper is the non-exclusivity and non-observability of contractual relations. In this paper, we characterize the optimal contract under the assumption that none of the labor and credit relations an agent engages in can be observed by an individual firm in an economy where the agent's productivity is privately known by the worker. ${ }^{2}$ We interpret this friction as reflecting both the costs that a firm might incur when monitoring the transactions agents engage in and the inability of firms to offer contracts contingent on the agents' actions with other firms in the economy.

The environment studied is a finite horizon dynamic Mirrleesian economy in which agents are privately informed about idiosyncratic labor productivity shocks that evolve over time. Agents wish to insure this risk by signing contracts with insurance providers (firms). Agents are not limited to a single insurance/labor relationship and can sign contracts with multiple firms. The contracting arrangements are private information of the contracting parties. In general, given this friction, the communication between agent and firms cannot be limited to the exogenous private shock of agents as in the case of observable contracts. Firms

\footnotetext{
1 The Panel Study of Income Dynamics reports a measure of income transfer received by households for the years 1969 to 1985 . We find that, in a given year, $24 \%$ of the households report receiving a transfer and $67 \%$ of the households received a transfer at some stage. These transfers are significant, averaging \$1,930 (1983 dollars) and represent between $70 \%$ to $90 \%$ of total food expenditures.

2 The characterization under exclusive contracts is well understood. See Prescott and Townsend (1984).
} 
might also seek information about the other relations the agent has engaged in. To accommodate this need, we extend the results in the common agency literature (see Peters, 2001; Martimort and Stole, 2002, and Epstein and Peters, 1999) to our dynamic environment and characterize equilibrium using a menu game. In this game, each firm offers collections of payoff relevant alternatives-menus-and delegates to the agent the choice within these menus. The choice of the agent from a menu can reveal information about his type and the other contractual arrangements in which he might be involved. We impose no restriction on the contracts that firms can offer. A firm can, for example, offer a spot labor contract, a linear inter-temporal borrowing and saving contract, a state contingent dynamic insurance contract, and so on. Hence, any contract offered-either on or off-equilibrium-is determined as a result of the strategic competition among firms. This highlights a key feature of this environment: any side-trading opportunity agents have access to arises endogenously. From a methodological standpoint, we see the contribution of this paper as showing the application of the common agency literature to dynamic social insurance problem.

Our main result is that the non-exclusivity of contracts removes the possibility of additional insurance beyond self-insurance, with only linear contracts arising in equilibrium. We show this result in two steps: first we characterize the conditions an equilibrium must satisfy; next, we prove that an equilibrium exists.

Going into more details, we show that the equilibrium allocation must satisfy three optimality conditions. First, the inter-temporal marginal rate of substitution between consumption at time $t$ and consumption at $t+1$ is equal to the marginal rate of transformation (a standard Euler equation holds). ${ }^{3}$ Second, the marginal rate of substitution between consumption and leisure is equated to the marginal productivity for any time and any history. ${ }^{4}$ Third, the net present value of the transfers received in equilibrium is equal to zero for every agent in the economy. These optimality conditions imply that the unique equilibrium allocation is equivalent to an economy in which agents can trade non-contingent bonds and are paid their marginal productivity, and in which there is no redistribution. The intuition for this result is the following. In our environment, the constrained efficient provision of insurance is provided both intra-temporally with wages and inter-temporally with non-linear returns on savings. The provision of insurance, due to private information on types, implies that some types receive a wage below marginal product or a return on borrowing and saving different than the marginal rate of transformation. This introduces profitable side trades opportunities for either labor services or credit. We show that the availability of side trades are sufficient to remove any possibility for insurance. It is worth highlighting that even for a good such as labor that cannot be freely traded (a worker cannot work a negative amount with a given firm), the opportunity to work on the side is sufficient to remove any non-linearity in wages. This is because side trades will imply either the contract being linear or the contract providing a form of negative insurance.

Finally, we show that an equilibrium exists. This is a key step since, as noted by Myerson (1982), the existence of equilibria with multiple principals is not always guaranteed. We show that to sustain the unique equilibrium allocation, two ingredients are necessary. First, more than

\footnotetext{
3 If contracts are exclusive, the Euler equation does not hold, and agents are savings constrained (see Rogerson, 1985 and Golosov et al., 2003).

4 This is also different with respect to the exclusive contracting environment (see, for example, Mirrlees, 1971 and Golosov et al., 2006), where this relation holds only for the highest skill type, while all of the remaining types face a distortion on the intratemporal margin that discourages consumption and hours provided.
} 
one firm (the incumbents) must be active in equilibrium. Second, incumbent firms must offer contracts that will not be chosen in equilibrium: latent contracts. These contracts have the specific role of deterring deviations of other entrants. ${ }^{5}$ For example, suppose the incumbent were to offer the equilibrium allocation without any additional latent contract. Since the allocation is the most profitable non-redistributive contract, any entrant must offer a contract that features some redistribution. The worker will accept the entrant's contract. However, if the incumbent offers a latent contract that allows an agent to perform a side trade, the contingent contract offered by the entrant can be made unprofitable.

\section{Related literature}

The results, linking side trading and linear contracts, are reminiscent of Allen (1985), Hammond (1987), Cole and Kocherlakota (2001). ${ }^{6}$ We contribute to this literature by explicitly modeling the non-cooperative competition between firms, determining endogenously the market structure and showing that an equilibrium exists. Specifically, Hammond (1987) characterizes, in a static exchange economy, the constrained efficient allocation which is robust to re-trading among agents. A linear price for goods emerges in equilibrium. Some of the differences with respect to this paper are the equilibrium concept adopted, and that in our environment some of the trades agents can make are one-sided: agents can sell leisure to firms but cannot buy it.

This paper is related to the literature on optimal social insurance contracts and its implementation through taxation commonly referred to as the new dynamic public finance. ${ }^{7}$ In general, the environment studied in this literature assumes that insurance is provided by a unique providerthe government-who perfectly controls both consumption and labor decisions of the agents. With respect to this literature, this paper provides an important message. Our main result suggests that the constrained efficient allocation cannot be implemented in decentralized environments when the policy maker is unable to observe any side contracting involving labor and inter temporal borrowing and saving. This is because the presence of hidden and self-enforcing activities (for both consumption and labor) might undo any incentives the government provides through taxes. Related to this last point, our work is also related to the literature on optimal contracts in the presence of hidden trades. ${ }^{8}$ In particular, Cole and Kocherlakota (2001) show that, in a private information endowment economy, the equilibrium is equivalent to self-insurance when agents can secretly save in a storage technology. In an environment similar to ours, Golosov and Tsyvinski (2007) characterize equilibrium when agents can engage in hidden trades of Arrow-Debreu securities. They show that a standard Euler equation holds, and that the decentralized equilibrium is not efficient since firms do not internalize the effects of the contracts offered on the market rate of return. ${ }^{9}$ This paper can be seen as a generalization of the previous two papers. In the previous papers the re-contracting possibilities are assumed to exist exogenously (a market with linear prices or a storage technology), while in this paper the re-contracting market is a result of an equilibrium game between insurance providers.

This paper is also related to a growing literature on optimal contracting in non-exclusive relationships. Biais et al. (2000) consider an environment where competing traders provide liquidity

\footnotetext{
5 In our environment, restricting to direct mechanisms, while not restrictive in an environment with exclusive contracts, results in non-existence of the equilibrium.

6 For linearity in the context of price discrimination, refer to Armstrong and Vickers (2010) and references therein.

7 For a review, refer to Golosov et al. (2006), Kocherlakota (2010) and Albanesi (2008).

8 See also, Golosov and Tsyvinski (2007), Abraham and Pavoni (2005) and Abraham et al. (2011).

9 See also Farhi et al. (2009) for a related environment.
} 
to a risk-averse agent who is privately informed on the value of an asset. Attar et al. (2011) consider a "market for lemons" under non-exclusivity. Also, Bisin and Guaitoli (2004) analyze a static moral hazard environment under non-exclusive contracting. Finally, for an adverse selection environment under non-exclusivity refer to Attar et al. (2014) and Ales and Maziero (2013).

The paper is organized as follows. In Section 2, we describe the environment and show that any equilibrium can be implemented by a menu game. Section 3 characterizes the equilibrium of our benchmark environment and shows that it is equivalent to self-insurance. In Section 4 we show that an equilibrium exists and also show that latent contracts are necessary to implement the equilibrium allocation. In Section 5 we expand to the case with infinite horizon. Finally, Section 6 concludes the paper. The Appendix contains most of the proofs.

\section{Environment}

In large part, the environment is a standard dynamic Mirrleesian environment as in Golosov et al. (2003) and Albanesi and Sleet (2006). ${ }^{10}$ The key difference is in the nature of the competition and equilibrium which we describe in the next subsection.

There is a continuum of measure one of ex ante identical agents and countably many firms (insurance providers). We assume free entry. The economy lasts for a finite number $T$ of periods (the case with $T=\infty$ is discussed in Section 5). Agents' period utility is defined over consumption $c$ and labor $l$ and is given by $u(c)-v(l)$. Assume that $u: \mathbb{R}_{+} \rightarrow \mathbb{R}$ is a twice continuously differentiable, increasing and strictly concave function, in addition $\lim _{c \rightarrow 0} u^{\prime}(c)=\infty$ and $\lim _{c \rightarrow \infty} u^{\prime}(c)=0$; and $v: \mathbb{R}_{+} \rightarrow \mathbb{R}$ is a twice continuously differentiable, increasing, and strictly convex function, in addition $\lim _{l \rightarrow 0} v^{\prime}(l)=0$ and $\lim _{l \rightarrow \infty} v^{\prime}(l)=\infty$. Agents discount future utility at rate $0<\beta<1$. At every time $t=1,2, \ldots, T$ each agent draws a privately observed productivity shock $\theta_{t} \in \Theta$, where $\Theta$ is a finite set containing $N$ elements and its smallest element is strictly positive. Requiring an always strictly positive productivity shocks implies that non-negativity of consumption can always be satisfied. The shock is distributed according to a probability distribution $\pi(\cdot)$ and is independent and identically distributed over time and across agents. ${ }^{11}$ Let $\theta^{t}=\left(\theta_{1}, \ldots, \theta_{t}\right)$ denote the history of uncertainty of an agent up to (and including) time $t$. Following the Mirrleesian tradition, we assume the productivity and labor input are private information of the agent.

Firms are risk neutral and maximize expected profits. Each firm owns two technologies. The first one allows the firm to transfer resources over time at a fixed per period rate $1 / q$, where $0<q \leq 1$. The second one allows the firm to generate output (denoted by $y$ ) combining agent's productivity $(\theta)$ with the provided quantity of labor $(l)$. Output is produced according to the linear production function $y=\theta \cdot l$. Agents can contract with firms for employment and insurance against the productivity shocks. ${ }^{12}$ The shock $\theta$ and the amount worked $l$ are private information of the agent. We denote with $b$ the additional transfer beyond $y$ transferred from the firm to the agent (note that $b$ can be negative). In an environment where an agent of type $\theta$ deals exclusively with one firm providing labor equal to $l$ and receiving transfer $b$, his consumption will be given by $c=y+b$ where $y$ is the output produced. Period profits of the firm, given transfer $b$, are

10 For finite horizon life-cycle models refer to Ales and Maziero (2008), Weinzierl (2011), Fukushima (2010), Golosov et al. (2016), and Farhi and Werning (2013).

11 Allowing for a time-varying distribution of shocks does not alter the results in this paper.

12 Ownership of a storage technology by the agent does not affect the results in the paper. 
defined as $V(b)=-b$. The output produced with the firm's technology $y$ is observable only by that firm.

\section{Competition and menu games}

We next describe the type of contracts offered by firms to agents and the nature of the competition between firms. A novel feature of our environment is that agents can sign contracts simultaneously with more than one firm: contracts are non-exclusive. If contracts are exclusive, the environment described so far is equivalent to a standard dynamic Mirrleesian environment. In this case, the revelation principle shows that the communication between agents and firms can, without loss of generality, be restricted to agents reporting their labor productivity to firms: a direct mechanism where the message space identifies with the type space. Under non-exclusive contracts, restricting the firm to communicate via a direct mechanism may not be sufficient to separate agents with different labor productivities. This is because the preference ordering of agents over allocations is influenced not only by their exogenous productivities, but also by the set of contracts they have accepted from other firms. For example the willingness to provide additional effort depends whether or not the agent is providing effort to other firms. Since firms need to elicit from the agent what additional contracts he has access to and has accepted, limiting the communication to the agents' productivity may not be without loss of generality.

Expanding the message space beyond the type space provides a significant challenge for characterization. To resolve this issue, we follow the common agency literature and characterize the environment defining a menu game between firms. ${ }^{13}$ The key idea is that any communication in the original communication mechanism can be replaced by firms offering menus of payoffrelevant alternatives and delegating to the agents the choice within this menu. In Appendix A we adapt the delegation principle proved by Peters (2001) and Martimort and Stole (2002) to our environment. ${ }^{14}$ This principle states that, without loss of generality, the equilibrium outcomes of any communication game can be implemented as an equilibrium of a menu game, which we now describe.

\section{The problem of the agent and of the firm}

At time zero, before any uncertainty is realized, agents sign contracts with multiple firms. ${ }^{15}$ In terms of notation, the pair $\left(b_{t}^{i}, y_{t}^{i}\right)$ denotes the output requirement $\left(y_{t}^{i}\right)$ and the additional transfers received $\left(b_{t}^{i}\right)$ from firm $i$ at time $t$. We assume that the terms of the contract between an agent and a firm $i$ are only observed by the parts involved and are not observed by other firms. This implies that the contract offered by one firm cannot be contingent on the contracts offered by other firms. In addition, each firm $i$ observes only output produced $y_{t}^{i}$ and not the output (nor the labor) pertaining to other firms.

\footnotetext{
13 Epstein and Peters (1999) show that in games with multiple principals, there exists a universal type space for which the revelation principle holds. This space must be rich enough to allow agents and firms to communicate the exogenous type space and the information about the contracts offered by other principals. This universal type space is hard to characterize in applications; hence, we do not follow their approach. See also Pavan and Calzolari (2010) for an alternative characterization of the incentive-compatibility constraints in common agency problems.

14 A key difference between our environment and Martimort and Stole (2002) is that agents choose a communicationcontingent contract from each firm $i$ before any uncertainty is realized. This is important since at time 0 , agents are identical. Thus, it might be possible to extract more information about the contracts being offered by other firms.

15 In the environment, agents and firms are fully committed to the contracts signed at time zero. Hence, issues related to renegotiation are not a concern. For environment featuring renegotiation refer to: Kocherlakota (1996), Ales and Sleet (2014) and references therein.
} 
In each period (as in Rochet, 1986 and Guesnerie, 1998), agents pick their optimal choice for $\left(b_{t}^{i}, y_{t}^{i}\right.$ ) within a set (a menu) offered by firm $i$. Denote by $C_{t}^{i} \in \mathbb{R} \times \mathbb{R}_{+}$such set. A firm, over time, may wish to allow for history dependance in the alternatives it makes available to the agent. Given this we denote by $C_{t}^{i}\left(b^{i, t-1}, y^{i, t-1}\right) \in \mathbb{R} \times \mathbb{R}_{+}$the set of choices available to the agent from firm $i$ at time $t$ having previously chosen $\left(b^{i, t-1}, y^{i, t-1}\right)$ from firm $i$. We do not impose any ad hoc restrictions on the contracts offered by each firm. To guarantee the agents' problem has a solution, we require menus to be compact sets. With this specification, a firm can offer a contract for the entire time horizon $t=1, \ldots, T$; for a particular set of dates; only credit contracts $\left(y_{t}=0, \forall t\right)$; only labor contracts (where the transfer $b$ does not display history dependance over time); or both. We also do not impose any specific structure on the contracts; in particular, we do not restrict to linear contracts. We do, however, limit the analysis to deterministic menus and contracts.

Example 1. To illustrate the nature of a menu in our environment we display two simple examples. Consider first an economy that lasts for 2 periods. Firm $i$ offers the following menu: $C^{i}=\left\{C_{1}^{i}, C_{2}^{i}\left(b_{1}^{i}, y_{1}^{i}\right): C_{1}^{i}=\left\{(b, 0) \in \mathbb{R}^{2}\right\}, C_{2}^{i}(b, 0)=\{-b / q, 0\}\right\}$. With this menu, the firm allows an agent to borrow (or save) an amount $b$ in period 1 , and the agent must pay (or receive) the amount $b / q$ at time 2 . In this menu, there are no labor choices. In this example, the menu available at time 2 depends on the choice made at time 1 . As a second example, suppose firm $i$ offers the following menu: $\tilde{C}^{i}=\left\{C_{t}^{i}=(0, \delta): \delta \geq 0, \forall t\right\}$. With this menu, firm $i$ allows an agent to generate any amount of output $\delta$ in any period $t$. Firm $i$ provides no additional transfer to the agent.

Denote by $C^{i}$ the history contingent set of menus chosen from firm $i$ at time zero. Before describing the problem of the agent at time 0 , we describe the problem of the agent at time $1 \leq t \leq T$. Conditional on having accepted the menus $C=\left\{C^{1}, \ldots, C^{I}\right\}$ from firms $i \in\{1, \ldots, I\}$ at time 0 , agent's payoff is:

$$
U\left(\left\{C^{1}, \ldots, C^{I}\right\}\right)=\max _{c, l, y, b} \sum_{t=1}^{T} \beta^{t-1} \sum_{\theta_{t} \in \Theta} \pi\left(\theta_{t}\right)\left[u\left(c_{t}\left(\theta^{t-1}, \theta_{t}\right)\right)-v\left(l_{t}\left(\theta^{t-1}, \theta_{t}\right)\right)\right]
$$

subject to:

$$
\begin{aligned}
& c_{t}\left(\theta^{t}\right)=\sum_{i=1}^{I}\left(y_{t}^{i}\left(\theta^{t}\right)+b_{t}^{i}\left(\theta^{t}\right)\right) ; \quad l_{t}=\sum_{i=1}^{I} l_{t}^{i}\left(\theta^{t}\right), \quad \forall t, \theta^{t} . \\
& y_{t}^{i}\left(\theta^{t}\right)=\theta_{t} \cdot l_{t}^{i}\left(\theta^{t}\right), \quad \forall t, \theta^{t}, i \in\{1, \ldots, I\} . \\
& \left(b_{t}^{i}\left(\theta^{t-1}, \theta_{t}\right), y_{t}^{i}\left(\theta^{t-1}, \theta_{t}\right)\right) \in C_{t}^{i}\left(b^{i, t-1}\left(\theta^{t-1}\right), y^{i, t-1}\left(\theta^{t-1}\right)\right), \quad \forall t, \theta^{t}, i \in\{1, \ldots, I\} . \\
& c_{t}(\theta)^{t} \geq 0, \quad \forall t, \theta^{t} ; \quad l_{t}^{i}\left(\theta^{t}\right) \geq 0, \quad \forall t, \theta^{t}, i \in\{1, \ldots, I\} .
\end{aligned}
$$

Constraint (1) takes into account that the total consumption of the agent is the sum of the output produced and the transfers received from each firm $i$. It also takes into account that the total labor provided by the agent is the sum of all labor provided to all firms $i$. Constraint (2) is standard in the Mirrleesian literature and relates output produced $(y)$ with the productivity of the agent and the labor input provided. It is worth stressing that each firm $i$ is only able to observe $y^{i}$ and not separately $\theta$ or $l$. Nor it will be able to observe $y^{j}$ for $j \neq i$. Constraint (3) takes into account that choices of the agent impact the set of possible choices that an agent can take in the future. 
Finally, constraint (4) guarantees that total consumption and the labor input for each firm are non-negative. Given the set of menus accepted at time $0, C=\left\{C^{1}, \ldots, C^{I}\right\}$, let $\hat{y}[C]$ and $\hat{b}[C]$ be a solution to the problem of the household described in $(\mathrm{HH})$. In addition let $\hat{y}_{t}^{i}[C]\left(\theta^{t}\right)$ and $\hat{b}^{i}[C]\left(\theta^{t}\right)$ be an element of the optimal choice of an agent with history $\theta^{t}$ in the menu offered by firm $i$.

We now write the profits for firm $i$ when agents accept contract $C^{i}$ and contracts $C^{-i}$ from other firms different than $i$. We have:

$$
V\left(C^{i}, C^{-i}\right)=-\sum_{t=1}^{T} q^{t-1} \sum_{\theta_{t} \in \Theta} \pi\left(\theta_{t}\right) \hat{b}^{i}[C]\left(\theta^{t}\right) .
$$

To allow for competition at time zero, we allow firms to offer multiple menus at this stage. Denote by $\mathcal{S}^{i}$ the collection of menus (a set of $C^{i}$ ) offered by firm $i$ at time zero. As an example of such collection, consider the two menus in Example 1, the set of menus offered by firm $i$ is $\mathcal{S}^{i}=\left\{C^{i}, \tilde{C}^{i}\right\}$. Let $\mathcal{S}$ be the collection of all $\mathcal{S}^{i}$. Without loss of generality, each firm can always offer the null contract. Let $I$ be the equilibrium number of firms that offers a collection of menus $\mathcal{S}^{i}$ different than the null one. In this paper, we refer to these $I$ firms as the "incumbents" (or as being active in equilibrium), while the remaining firms will referred to as the "entrants." The problem of the agent at time zero, taking as given the number of active firms $I$ and the collections of menus offered by these firms $\mathcal{S}^{i}$, is:

$$
\begin{aligned}
& \mathcal{U}(\mathcal{S})=\max _{C^{1}, \ldots, C^{I}} U\left(\left\{C^{1}, \ldots, C^{I}\right\}\right) \\
& \text { s.t. } \quad C^{i} \in \mathcal{S}^{i}, \quad \forall i \in\{1, \ldots, I\} .
\end{aligned}
$$

Let $\hat{C}[\mathcal{S}$ ] be a solution to the time zero household problem when all firms offer $\mathcal{S}$. We now write the problem of the firm at time zero. Each firm $i$, taking as given $\mathcal{S}^{-i}$ and the optimal replies of the agents $\hat{C}[\mathcal{S}]$, solves the following:

$$
\begin{aligned}
& \max _{\mathcal{S}^{i}} V\left(\hat{C}^{i}[\mathcal{S}], \hat{C}^{-i}[\mathcal{S}]\right) \\
& \text { s.t. } \quad \hat{b}_{t}^{i}\left(\theta^{t}\right) \in \hat{C}_{t}^{i}\left(\hat{b}^{i, t-1}, \hat{y}^{i, t-1} \mid \hat{C}^{i}\right), \hat{C}_{t}^{i}\left(\hat{b}^{i, t-1}, \hat{y}^{i, t-1} \mid \hat{C}^{i}\right) \in \hat{\mathcal{S}}^{i} \\
& \quad \hat{b}_{t}^{-i}\left(\theta^{t}\right) \in \hat{C}_{t}^{-i}\left(\hat{b}^{-i, t-1}, \hat{y}^{-i, t-1} \mid \hat{C}^{-i}\right) \quad \text { and } \quad \hat{C}_{t}^{-i}\left(\hat{b}^{-i, t-1}, \hat{y}^{-i, t-1} \mid \hat{C}^{-i}\right) \in \hat{\mathcal{S}}^{-i} .
\end{aligned}
$$

The constraints in this problem incorporate the optimal replies of agents within the contracts offered by firm $i$ (constraint (7)) and within the contracts offered by the other firms (constraint (8)). It thus make explicit the fact that when one firm changes the contracts offered, the optimal choices of the agents in the contracts offered by other firms might also change. As a summary of the environment, we next formally define the timing of the game.

- At time 0:

1. Each firm $i$ simultaneously offers a collection of menu $\mathcal{S}^{i}$;

2. Assume $I$ firms offer non-null menus. For all $i \in I$, agents choose $C^{i} \in \mathcal{S}^{i}$;

- For every time $1 \leq t \leq T$ :

1. Agent learns his private type $\theta_{t}$;

2. For all $i \in I$, agents choose $\left(b_{t}^{i}, y_{t}^{i}\right) \in C_{t}^{i}\left(b_{t-1}^{i}, y_{t-1}^{i}\right)$;

3. Payoffs are realized. 
We are now ready to define an equilibrium for our environment.

Definition 1 (Equilibrium of menu games). A pure strategy equilibrium of a menu game is a number of firms $I$; a collection of menus $\hat{\mathcal{S}}=\left\{\hat{\mathcal{S}}^{1}, \ldots, \hat{\mathcal{S}}^{I}\right\}$; agents' choices at time zero $\hat{C}=$ $\left\{\hat{\mathcal{C}}^{1}, \ldots, \hat{\mathcal{C}}^{I}\right\}$; agents choices at time $t:\left(\hat{b}_{t}^{i}, \hat{y}_{t}^{i}\right)$, for all $i$ and $t \in\{1, \ldots, T\}$, such that:

1. For all $t,\left(\hat{b}_{t}, \hat{y}_{t}\right)$ solves the household problem in $(\mathrm{HH})$.

2. $\hat{C}$ solves the time zero household problem in (HH - time 0$)$.

3. Firm choices at time 0 , for each $i \in I$, taking as given the choices of the other firms $\hat{\mathcal{S}}^{-i}, \mathcal{S}^{i}$ solves the firm problem in (Firm).

4. There is no $\mathcal{S}^{\prime}$ such that $V\left(\mathcal{S}^{\prime}, \hat{\mathcal{S}}\right)>0$.

The definition of equilibrium is somewhat standard. In conditions 1. and 2., agents maximize expected utility at time 0 and in every future period $1 \leq t \leq T$; condition 3 . guarantees that firms maximize profits; and condition 4. implies that there is no contract left outside of the equilibrium that would otherwise earn positive profits. It is worth emphasizing that the problem of each firm $i$ is affected by the choices of other firms via the action of the agent. This is true both at time zero and at each period $t$. Firms compete playing a Nash game at time zero taking this into account. Specifically, the constraints on the firm's problem require that, for any menu a firm offers, the choice of the agents in the menus offered by other firms are according to agents' best reply. It takes into account the fact that a firm $i$, by changing the menu it offers, might imply that agents' choices in the menu offered by other firms are also different.

The previous definition of equilibrium does not impose any restriction on the size of a menu. A menu can contain more alternatives than the cardinality of the type space, implying that in every period some allocations are not chosen in equilibrium. Similarly, at time 0 a firm might offer more than one set of contracts, also implying that some contracts are offered and not chosen by agents in equilibrium. We denote a contract as latent if it is offered in equilibrium by a firm but is not chosen in equilibrium by any agent. In this paper, we show that in this environment with competition under non-exclusivity, latent contracts have a fundamental role in sustaining equilibrium allocations by preventing other firms from deviating to other contracts. This aspect was first described in Arnott and Stiglitz (1991).

\section{Equilibrium characterization}

In the following two sections, we show the main result of this paper: there exists a unique equilibrium allocation of a menu game, and it coincides with the equilibrium of a self-insurance economy similar to Huggett (1993), Aiyagari (1994), Kaplan and Violante (2010). We proceed in two steps. First, in this section, we prove that any equilibrium must satisfy three conditions: the marginal rate of substitution between consumption and leisure is equal to marginal productivity for all agents; the standard Euler equation holds; and the net-present value of the transfers received under any history of shocks is zero. These conditions are the sufficient first-order conditions of a self-insurance economy. Second, in Section 4 we show an equilibrium exists.

\subsection{Characterization under exclusive contracts}

Before characterizing the optimality conditions in our environment, we review two robust equilibrium conditions that hold in an environment like ours but in which there is competition be- 
tween insurance providers and contracts are exclusive. ${ }^{16}$ When contracts are exclusive, Prescott and Townsend (1984) show that in a general class of private information economies, the first welfare theorem holds. The decentralized economy is equivalent to a planning problem that maximizes the ex ante lifetime utility of the agents subject to feasibility and incentive compatibility constraints. In this environment, the following conditions must hold:

1. In every period and for every history, the marginal rate of substitution between consumption and leisure is equated to the marginal productivity only for the highest type (originally shown by Mirrlees, 1971 and by Stiglitz, 1982 for a two-type case):

$$
\begin{aligned}
& u^{\prime}\left(c_{t}(\bar{\theta})\right)=\frac{1}{\bar{\theta}} v^{\prime}\left(\frac{y_{t}(\bar{\theta})}{\bar{\theta}}\right), \\
& u^{\prime}\left(c_{t}(\theta)\right)>\frac{1}{\theta} v^{\prime}\left(\frac{y_{t}(\theta)}{\theta}\right), \quad \forall \theta \neq \bar{\theta}, \theta \in \Theta,
\end{aligned}
$$

where $\bar{\theta} \equiv \max _{\theta \in \Theta} \theta$. This result implies that in equilibrium all agents, besides the most productive one, prefer to provide additional effort if compensated at their own marginal product.

2. The marginal rate of substitution of consumption between any two periods differs from the inter-temporal rate of transformation for all types (the standard Euler equation does not hold):

$$
\frac{1}{u^{\prime}\left(c_{t}\left(\theta^{t}\right)\right)}=\frac{q}{\beta} E\left[\frac{1}{u^{\prime}\left(c_{t+1}\left(\theta^{t+1}\right)\right)} \mid \theta^{t}\right], \quad \forall t, \theta^{t} .
$$

This equation, derived originally by Rogerson (1985) and generalized in Golosov et al. (2003), Farhi and Werning (2008) and Garrett and Pavan (2013), implies that for all periods and for all histories: $u^{\prime}\left(c_{t}\left(\theta^{t}\right)\right)<\frac{\beta}{q} E\left[u^{\prime}\left(c_{t+1}\left(\theta^{t+1}\right)\right) \mid \theta^{t}\right]$. This condition implies that in equilibrium, at the rate $q$, agents would like to save more to raise the current marginal utility of consumption and lower next period's marginal utility of consumption. Intuitively, to encourage truthful revelation of the productivity shock in the future, it is optimal to make agents savings-constrained.

Both of the above conditions highlight how exclusive contracting precludes trades that agents would otherwise find optimal in a competitive environment. This observation is key in determining the properties of the equilibrium under non-exclusive contracting.

\subsection{Optimality conditions under non-exclusivity}

We now derive equilibrium conditions in the presence of non-exclusive contracts. The first result refers to the intra-temporal consumption and leisure choice. The next Lemma shows that the condition in equation (10) cannot hold when contracts are non-exclusive. This is because agents can always work any additional positive amount of time with other firms.

16 For a review of the results of constrained efficient allocation in dynamic Mirrleesian environments, refer to Salanié (2003), Golosov et al. (2006), and Kocherlakota (2010). 
Lemma 1. In equilibrium for every $t$ and for every $\theta^{t} \in \Theta^{t}$ we have:

$$
u^{\prime}\left(b_{t}\left(\theta^{t}\right)+y_{t}\left(\theta^{t}\right)\right) \leq v^{\prime}\left(\frac{y_{t}\left(\theta^{t}\right)}{\theta_{t}}\right) \frac{1}{\theta_{t}},
$$

where $b_{t}\left(\theta^{t}\right)=\sum_{i=1}^{I} b_{t}^{i}\left(\theta^{t}\right)$ and $y_{t}\left(\theta^{t}\right)=\sum_{i=1}^{I} y_{t}^{i}\left(\theta^{t}\right)$ and $\left\{b_{t}^{i}\left(\theta^{t}\right), y_{t}^{i}\left(\theta^{t}\right)\right\}_{i=1}^{I}$ are the contracts chosen by an agent with history $\theta^{t}$ from firm $i \in\{1, \ldots, I\}$ at time $1 \leq t \leq T$.

Proof. Suppose that for some $t$ and history $\theta^{t}$ equation (12) does not hold:

$$
u^{\prime}\left(b_{t}\left(\theta^{t}\right)+y_{t}\left(\theta^{t}\right)\right)>v^{\prime}\left(\frac{y_{t}\left(\theta^{t}\right)}{\theta_{t}}\right) \frac{1}{\theta_{t}} .
$$

Consider an entrant that offers the null contract at time $\tau \neq t$ and at time $t$ the menu $\widehat{C}_{t}=$ $\left\{\left(-\varepsilon, \delta^{*}(\varepsilon)\right),(0,0)\right\}$ where $\delta^{*}$ and $\varepsilon$ are constructed as follows. For some $\varepsilon>0$ and small, let $\delta^{*}(\varepsilon)$ be the solution of the following problem:

$$
\max _{\delta \geq 0} u\left(b_{t}\left(\theta^{t}\right)+y_{t}\left(\theta^{t}\right)+\delta-\varepsilon\right)-v\left(\frac{y_{t}\left(\theta^{t}\right)+\delta}{\theta_{t}}\right) .
$$

This problem can be interpreted as one in which additional effort is chosen (choosing $\delta / \theta_{t}$ ) when the compensation is given by $\delta-\varepsilon$. The necessary first order condition for this problem is:

$$
u^{\prime}\left(b_{t}\left(\theta^{t}\right)+y_{t}\left(\theta^{t}\right)+\delta^{*}\left(\varepsilon \mid \theta_{t}\right)-\varepsilon\right) \leq v^{\prime}\left(\frac{y_{t}\left(\theta^{t}\right)+\delta^{*}\left(\varepsilon \mid \theta_{t}\right)}{\theta_{t}}\right) \frac{1}{\theta_{t}} .
$$

Since (13) holds, if $\varepsilon=0$, the solution for the above problem features $\delta^{*}(0)>0$. From the Theorem of the Maximum, the solution $\delta^{*}(\cdot)$ is continuous. This implies there exists a $\varepsilon>0$ (sufficiently small) so that $\delta^{*}(\varepsilon)>0$. This contract delivers strictly positive profits, proportional to $\varepsilon$, and the agent is strictly better off given that his utility is higher in some history with positive probability. This contract is always profitable for the entrant even if other types $\tilde{\theta}_{t}$ accept the deviating contract. The only way to deter the above deviation is to have a latent contract that makes no agent willing to choose the deviation. However, if such a contract existed, it would have been chosen in the original equilibrium. Having found a profitable deviation, we reach a contradiction with condition 4 . in the definition of the equilibrium.

The proof relies on the fact that if condition (12) does not hold, it follows that the agent prefers to consume and work more (if compensated at his marginal product) than the equilibrium contract. Thus an entrant can make strictly positive profits offering a supplemental contract with more consumption and output. In Proposition 1, we strengthen the result and show that (12) holds with equality. The additional step required to show this cannot be proved as in the above Lemma. To see this consider the following: ruling out the opposite inequality, thus leading to (12) holding with equality, requires a reduction in output. Since agents cannot work negative hours, this deviation cannot be performed by an entrant and can only be offered by the incumbent.

The second result focuses on the inter-temporal consumption choice. When contracts are exclusive, the provision of incentives implies that agents are savings constrained. The following Lemma shows that this cannot happen under non-exclusivity. 
Lemma 2. In any equilibrium for every $\theta^{t} \in \Theta^{t}$, for all $t$, we have:

$$
u^{\prime}\left(c_{t}\left(\theta^{t}\right)\right)=\frac{\beta}{q} \sum_{\theta_{t+1}} \pi\left(\theta_{t+1}\right) u^{\prime}\left(c_{t+1}\left(\theta^{t+1}\right)\right),
$$

where $c_{t}\left(\theta^{t}\right)=\sum_{i=1}^{I}\left(b_{t}^{i}\left(\theta^{t}\right)+y_{t}^{i}\left(\theta^{t}\right)\right)$ for all $t$ and $\theta^{t}$.

Proof. In Appendix B.1.

The intuition for the result follows Allen (1985) closely. If the equilibrium allocation does not satisfy the Euler equation (16), an entrant firm can offer a savings (borrowing) contract at time $t$ with an implicit interest rate lower (higher) than the marginal rate of transformation. As long as this contract is accepted, the entrant makes strictly positive profits and the contract can be constructed in a way that provides higher utility to the agent.

Remark 1. Lemma 1 and 2 highlight how, under non-exclusivity, the equilibrium allocation cannot feature any positive distortions on the consumption-leisure margin (Lemma 1) or any on the inter-temporal consumption allocation (Lemma 2). These no-distortion results hinge on the ability of entrants to provide insurance contract at no costs. In the presence of small entry costs, reasoning similar to the previous Lemmas provide an upper bound on the magnitude of distortions that can be sustained in equilibrium. To make this point concrete, we focus on the consumption-leisure margin. Denote the intra-temporal distortion following history $\theta^{t}$ with $\tau_{t}\left(\theta^{t}\right)$, defined as:

$$
\tau_{t}\left(\theta^{t}\right)=1-v^{\prime}\left(\frac{y_{t}\left(\theta^{t}\right)}{\theta_{t}}\right) \frac{1}{\theta_{t}} / u^{\prime}\left(b_{t}\left(\theta^{t}\right)+y_{t}\left(\theta^{t}\right)\right) .
$$

Suppose that an entrant faces an entry cost equal to $\eta>0$ arbitrarily small to enter and offer a menu. In this case, Lemma 1 implies that for all $t$ and $\theta^{t}$ if $\eta=0$, in equilibrium we have that $\tau_{t}\left(\theta^{t}\right) \leq 0$. We next show that the fixed $\operatorname{cost}(\eta)$ introduces an upper bound on the distortions that can originate in equilibrium. Define $\delta\left[\tau_{t}\left(\theta^{t}\right)\right]$ as:

$$
v^{\prime}\left(\frac{y_{t}\left(\theta^{t}\right)+\delta\left[\tau_{t}\left(\theta^{t}\right)\right]}{\theta_{t}}\right) \frac{1}{\theta_{t}}=u^{\prime}\left(b_{t}\left(\theta^{t}\right)+y_{t}\left(\theta^{t}\right)+\delta\left[\tau_{t}\left(\theta^{t}\right)\right]\right) .
$$

The value $\delta\left[\tau_{t}\left(\theta^{t}\right)\right]$ represents the amount of additional effort required to satisfy the static first order condition when the equilibrium features a distortion equal to $\tau_{t}\left(\theta^{t}\right)$. If $\tau_{t}\left(\theta^{t}\right)>0$ then $\delta\left[\tau_{t}\left(\theta^{t}\right)\right]>0$. In addition, $\delta\left[\tau_{t}\left(\theta^{t}\right)\right]$ is increasing in $\tau_{t}\left(\theta^{t}\right)$. In equilibrium, in the presence of an entry cost $\eta$, we have that $\tau_{t}\left(\theta^{t}\right) \delta\left[\tau_{t}\left(\theta^{t}\right)\right] \leq \eta$. Suppose by contradiction that this is not the case so that

$$
\tau_{t}\left(\theta^{t}\right)>\frac{\eta}{\delta\left[\tau_{t}\left(\theta^{t}\right)\right]},
$$

then a deviation offering a contract $\left(-\varepsilon-\eta, \delta\left[\tau_{t}\left(\theta^{t}\right)\right]\right)$ for arbitrarily small $\varepsilon>0$ can be shown to improve the time zero utility of the agent and generate profits (net of entry costs) for the entrant equal to $\varepsilon$, hence reaching a contradiction.

The previous two Lemmas characterize the distortions that can occur in equilibrium. The next Lemma highlights the limits to the amount of insurance that can be provided in the environment with non-exclusive contracts. Before stating the Lemma, we define the following auxiliary value 
function. Consider the case of an agent with history $\theta^{t-1}$. Suppose the agent, together with the equilibrium allocation, has an amount of resources equal to $s$ in a simple borrowing-saving linear contract (as in Example 1). His continuation utility for $t \leq T$ is given by:

$$
\begin{array}{r}
W_{t}^{s}\left(\theta^{t-1}\right)[s]=\max _{\left\{s^{\prime}, e \geq 0\right\}} \sum_{\theta \in \Theta} \pi(\theta)\left[u \left(b_{t}\left(\theta^{t-1}, \theta\right)\right.\right. \\
\left.\left.+s-s^{\prime}+e\right)-v\left(\frac{y_{t}\left(\theta^{t-1}, \theta\right)+e}{\theta}\right)\right]+ \\
+\beta \sum_{\theta^{\prime} \in \Theta} \pi\left(\theta^{\prime}\right) W_{t+1}^{s}\left(\left(\theta^{t-1}, \theta\right), \theta^{\prime}\right)\left[\frac{s^{\prime}}{q}\right],
\end{array}
$$

and $W_{T+1}^{s} \equiv 0$. In addition, let $W_{t+1}\left(\theta^{t-1}, \theta_{t}\right)$ be the continuation utility that an agent with history $\left(\theta^{t-1}, \theta_{t}\right)$ receives from time $t+1$ onwards. We can now state the Lemma.

Lemma 3. For all $t$ and $\theta^{t-1}$ if $y_{t}\left(\theta^{t-1}, \theta_{t}\right) \geq y_{t}\left(\theta^{t-1}, \theta_{t}^{\prime}\right)$ for some $\theta_{t}, \theta_{t}^{\prime} \in \Theta$ then

$$
u\left(b_{t}\left(\theta^{t}\right)+y_{t}\left(\theta^{t}\right)\right)+\beta W_{t+1}\left(\theta^{t-1}, \theta_{t}\right) \geq u\left(b_{t}\left(\theta^{t-1}, \theta_{t}^{\prime}\right)+y_{t}\left(\theta^{t}\right)\right)+\beta W_{t+1}\left(\theta^{t-1}, \theta_{t}^{\prime}\right),
$$

where $\theta^{t}=\left(\theta^{t-1}, \theta_{t}\right)$ and:

$$
W_{t+1}\left(\theta^{t-1}, \theta_{t}\right)=W_{t+1}^{s}\left(\theta^{t-1}, \theta_{t}\right)[0] \geq W_{t+1}^{s}\left(\theta^{t-1}, \theta_{t}^{\prime}\right)\left[\frac{1}{q}\left(b_{t}\left(\theta^{t-1}, \theta^{\prime}\right)-b_{t}\left(\theta^{t-1}, \theta\right)\right)\right],
$$

where $W_{T+1}(\cdot)=0$.

Proof. In the proof, we suppress notation concerning the previous history $\theta^{t-1}$. We begin by looking at the proof of (17). Suppose the statement does not hold. Then for some $\theta_{t}, \theta_{t}^{\prime}$ we have that $y_{t}\left(\theta_{t}\right) \geq y_{t}\left(\theta_{t}^{\prime}\right)$ but $u\left(b_{t}\left(\theta_{t}\right)+y_{t}\left(\theta_{t}\right)\right)+\beta W_{t+1}\left(\theta_{t}\right)<u\left(b_{t}\left(\theta_{t}^{\prime}\right)+y_{t}\left(\theta_{t}\right)\right)+\beta W_{t+1}\left(\theta_{t}^{\prime}\right)$. As a first case, suppose that $y_{t}\left(\theta_{t}\right)>y_{t}\left(\theta_{t}^{\prime}\right)$, then an entrant can offer a menu containing the null contract and $\left(-\varepsilon, y_{t}\left(\theta_{t}\right)-y_{t}\left(\theta_{t}^{\prime}\right)\right)$, with $\varepsilon>0$ and small. This contract allows the agent to work additional hours for a small fee equal to $\varepsilon$. Given the availability of such a contract, agents of type $\theta_{t}$ can choose the allocation chosen by agents of type $\theta_{t}^{\prime}$ in the original equilibrium together with the contract offered by the entrant. By doing so they: (i) replicate their original output $y_{t}\left(\theta_{t}\right)$ and (ii) receive utility level $u\left(b_{t}\left(\theta_{t}^{\prime}\right)-\varepsilon+y_{t}\left(\theta_{t}\right)\right)+\beta W_{t+1}\left(\theta_{t}^{\prime}\right)>u\left(b_{t}\left(\theta_{t}\right)+y_{t}\left(\theta_{t}\right)\right)+$ $\beta W_{t+1}\left(\theta_{t}\right)$, where the last inequality follows from $\varepsilon$ being sufficiently small and the contradicting assumption. This choice enables agents of type $\theta_{t}$ to strictly increase his utility level relative to the proposed equilibrium. The entrant makes profit equal to $\varepsilon$ and a contradiction is reached. The case in which $y_{t}\left(\theta_{t}\right)=y_{t}\left(\theta_{t}^{\prime}\right)$ follows immediately since it implies a violation of the incentive constraint preventing agent of type $\theta_{t}$ reporting being of type $\theta_{t}^{\prime}$.

The proof of (18) proceeds similarly as the previous one. Suppose statement (18) is false. In this case, an agent of type $\theta_{t}$ can replicate the consumption and effort of his original allocation while reporting type $\theta_{t}^{\prime}$. In addition to the deviation described above, he will also borrow or save using a linear contract with an entrant. In this case, the deviating agent of type $\theta_{t}$ will have an additional asset position (with the entrant) equal to $s=b_{t}\left(\theta_{t}^{\prime}\right)-b_{t}\left(\theta_{t}\right)$. If (18) is violated, the deviation of the entrant strictly increases utility.

The previous Lemma highlights the limits to the provision of insurance under non-exclusive contracting. To see this, it is instructive to look at the case in which $t=T$. From condition (17), 
we have that if $y_{t}\left(\theta^{t-1}, \theta_{t}\right) \geq y_{t}\left(\theta^{t-1}, \theta_{t}^{\prime}\right)$ then $b_{t}\left(\theta^{t}\right) \geq b_{t}\left(\theta^{t-1}, \theta_{t}^{\prime}\right)$ : high-skilled agents work more and are compensated with higher transfer relative to low-skilled agents. In the proof of the Lemma, any positive amount of insurance transferred between the high- and low-skilled is prevented by deviations of entrants. These deviations allow skilled agents to choose the allocation designed for low-skilled agents and to work an additional amount. As discusses in Remark 1, the competitive structure assumed in the paper is crucial in deriving the results of Lemma 1 and 2. It is also the case for the previous Lemma. In this case, small entry costs can allow for the provision of small positive insurance. For example, in the previous $t=T$ case it is possible to sustain a $b_{t}\left(\theta^{t-1}, \theta_{t}^{\prime}\right)+\eta=b_{t}\left(\theta^{t}\right)$ in the presence of an entry cost $\eta$.

Remark 2. The previous Lemmas 1-3 share a common property. Their results hinge only on the ability of an entrant to offer a profitable contract that limits the ability of the incumbent to either induce distortions in the equilibrium allocation (Lemma 1 and Lemma 2) or to provide a positive amount of insurance (Lemma 3). It is important to observe that in proving the results, we do not require any additional knowledge about the nature of the equilibrium allocation. Moreover, the contracts offered by the entrants are linear: they do not require separating the type of the agents and are profitable the moment any agent accepts them. In this regard, the preceding Lemmas can be shown to hold with a more general set of assumptions than the ones imposed in the benchmark environment. For example, a modified version of the Lemmas hold relaxing the assumption on the separability of preferences or introducing serial correlation of shocks over time (this is because the entrant does not require any information on the type of the agent accepting their contracts). These assumptions are, however, critical for the remainder of the paper and are hence maintained throughout.

In the next Proposition, we show that in equilibrium the lifetime transfers received under any history are equal to zero. This implies that there is no cross-subsidization between types. We also show that the marginal rate of substitution (MRS) between consumption and leisure is equated to the marginal productivity after any history.

Proposition 1. In any equilibrium the following two conditions hold:

\section{Zero net present value of transfers:}

$$
\sum_{t=1}^{T} q^{1-t} b_{t}\left(\theta^{t}\right)=0 \quad \forall \theta^{T} \in \Theta^{T} .
$$

2. MRS equal to marginal productivity:

$$
u^{\prime}\left(b_{t}\left(\theta^{t}\right)+y_{t}\left(\theta^{t}\right)\right)=v^{\prime}\left(\frac{y_{t}\left(\theta^{t}\right)}{\theta_{t}}\right) \frac{1}{\theta_{t}} \quad \forall \theta^{t}, t,
$$

where $b_{t}\left(\theta^{t}\right)=\sum_{i=1}^{I} b_{t}^{i}\left(\theta^{t}\right)$ and $y_{t}\left(\theta^{t}\right)=\sum_{i=1}^{I} y_{t}^{i}\left(\theta^{t}\right)$ and $\left\{b_{t}^{i}\left(\theta^{t}\right), y_{t}^{i}\left(\theta^{t}\right)\right\}_{i=1}^{I}$ are the contracts chosen by an agent with history $\theta^{t}$ from firm $i \in\{1, \ldots, I\}$ at time $1 \leq t \leq T$.

Proof. In appendix B.2.

The proof of (19) is a direct consequence of a stronger result showed in the Appendix: in any period $t$, following any history, the continuation expected transfers are independent of the realiza- 
tion of uncertainty at time $t$. To show this result, we proceed in two steps. Following Lemma 3, we first show that for any two productivity realizations, the agent with higher output must receive a higher net present value of transfers. If not-which is the case of the allocation described in Mirrlees (1971)-an entrant can offer an additional labor opportunity leading to misreporting of the agent with high output. Second, we show that the net present value of transfers must be the same across the two types; failure from doing this would constitute a form of "negative" insurance. When looking at the payoff to the agent, such contract is dominated by a more profitable contract offered at time zero by an entrant that features no insurance. Given that continuation profits are independent of current realization, it is easy to show that a deviation of an incumbent leads to condition (19).

\subsection{Equivalence to self-insurance}

The previous results show that the equilibrium allocation satisfies a standard Euler equation (16), that the marginal rate of substitution between consumption and leisure is equated to marginal productivity in every period (20), and that the net present value of transfers received under any history is equal to zero, so that there is no redistribution (19). These equilibrium conditions are the same optimality conditions that hold in a decentralized economy in which agents can borrow and save at rate $R=1 / q$. In this section, we formalize this argument. Let $\left\{c^{*}, y^{*}\right\}=\left\{c_{t}^{*}\left(\theta^{t}\right), y_{t}^{*}\left(\theta^{t}\right)\right\}_{t=1}^{T}$ be the solution to the following problem:

$$
\begin{array}{r}
\max _{\left\{c_{t}, y_{t}\right\}_{t=1}^{T}} \sum_{t=1}^{T} \sum_{\theta^{t}} \beta^{t-1} \pi\left(\theta^{t}\right)\left[u\left(c_{t}\left(\theta^{t}\right)\right)-v\left(\frac{y_{t}\left(\theta^{t}\right)}{\theta_{t}}\right)\right] \\
\text { s.t. } \quad \sum_{t=1}^{T} \frac{c_{t}\left(\theta^{t}\right)-y_{t}\left(\theta^{t}\right)}{R^{1-t}}=0, \quad \forall \theta^{T}, \\
c_{t}\left(\theta^{t}\right) \geq 0, \quad y_{t}\left(\theta^{t}\right) \geq 0, \quad \forall t, \theta^{t} .
\end{array}
$$

The above is a standard incomplete market self-insurance environment (with fixed returns) similar to the one analyzed in Huggett (1993), Aiyagari (1994), and Kaplan and Violante (2010). We have that:

Proposition 2. Let $\{\hat{b}, \hat{y}\}=\left\{\hat{b}_{t}\left(\theta^{t}\right), \hat{y}_{t}\left(\theta^{t}\right)\right\}_{t=1}^{T}$ be the equilibrium allocation of a menu game. Let the agents' consumption be $\hat{c}_{t}\left(\theta^{t}\right)=\hat{b}_{t}\left(\theta^{t}\right)+\hat{y}_{t}\left(\theta^{t}\right)$ for all $\theta^{t}$ and for all $t$. If $R=1 / q$, $c_{t}^{*}\left(\theta^{t}\right)=\hat{c}_{t}\left(\theta^{t}\right)$ and $y_{t}^{*}\left(\theta^{t}\right)=\hat{y}_{t}\left(\theta^{t}\right)$ for all $\theta^{t}$ and for all $t$.

Proof. The first order conditions of (21) are:

$$
\begin{aligned}
u^{\prime}\left(c_{t}\left(\theta^{t}\right)\right) & =\beta R \sum_{\theta_{t+1}} u^{\prime}\left(c_{t}\left(\theta^{t+1}\right)\right) \pi\left(\theta_{t+1}\right), \\
u^{\prime}\left(c_{t}\left(\theta^{t}\right)\right) & =\frac{1}{\theta_{t}} v^{\prime}\left(\frac{y_{t}\left(\theta^{t}\right)}{\theta^{t}}\right), \\
\sum_{t=1}^{T} \frac{c_{t}\left(\theta^{t}\right)-y_{t}\left(\theta^{t}\right)}{R^{1-t}} & =0, \quad \forall \theta^{T} .
\end{aligned}
$$


A solution to (21) exists. Also, the maximization problem (21) has a strictly concave objective function and the constraint set is convex; hence, the first order conditions are necessary and sufficient for the optimum and the optimum is unique. Given Lemma 2 and Proposition 1, we have that $\{\hat{b}, \hat{y}\}$ also satisfies (22), (23) and (24); the result follows immediately.

In its entirety, the previous proposition highlights how the presence of non-exclusivity and nonobservability of contracts limits the ability of firm to provide insurance. What is important here is that the contracts (the menus) offered by firms arise as part of the equilibrium. This is the key difference with respect to previous work as in Allen (1985) or Cole and Kocherlakota (2001). From a methodological standpoint, a contribution of this paper is to show how to characterize the equilibrium menus games by showing the applicability of the common agency literature to the study of dynamic insurance problems.

A natural question concerns the institutional details that allow the decentralization with linear contracts to occur. For example, a concern might be on the long lasting commitment of a lender (or borrower) to a borrowing or saving contracts. To enforce commitment we can think of an environment where both agents and firms have access to an enforcement mechanism ("a court") upon the payment of a cost. If this cost is paid, the terms of the contract between the two parties in consideration become public, and this court can enforce a punishment to the party that reneged on the contract. If either firms or agents falsely report a breach of the contract, they can also be punished by court. This punishment can be made large enough so that in equilibrium neither firms nor agents will renege on the contracts signed.

\subsection{Discussion}

The key result of this section is that the equilibrium allocation does not feature any additional insurance beyond what can be achieved by self-insurance. In what follows, we provide some additional intuition for this result. Consider the history contingent transfers $b_{t}(\cdot)$ received by agents in equilibrium. Let:

$$
\mathbf{b}_{t}\left(\theta^{t-1}\right)=\sum_{s=0}^{T-t} q^{s} \sum_{\theta^{s}} \pi\left(\theta^{s}\right) b_{t}\left(\theta^{t-1}, \theta^{s}\right),
$$

where with slight abuse of notation we denoted $\pi\left(\theta^{s}\right)$ as the probability of the history $\theta^{s}$ (of length $s$ ) occurring. In the context of a self-insurance equilibrium, the quantity $\mathbf{b}_{t}\left(\theta^{t-1}\right.$ ) can be interpreted as the assets available at time $t$ to an agent with shock history $\theta^{t-1}$. At time $t$, following a history $\theta^{t-1}$ and a realization $\theta_{t}$, ex-post assets are given by: $A_{t}\left(\theta^{t-1}, \theta_{t}\right)=$ $b_{t}\left(\theta^{t-1}, \theta_{t}\right)+q \cdot \mathbf{b}_{t+1}\left(\theta^{t}\right)$. In a self-insurance equilibrium, for all $t$ and $\left(\theta^{t-1}, \theta_{t}\right)$ we have that $A_{t}\left(\theta^{t-1}, \theta_{t}\right)=\mathbf{b}_{t}\left(\theta^{t-1}\right)$ : the available assets at time $t$ do not change upon the realization of the time- $t$ shock. In general insurance contracts the equality between the ex ante and ex post (at time $t$ ) level of assets need not hold. Without loss of generality, we can then write:

$$
A_{t}\left(\theta^{t-1}, \theta_{t}\right)=b_{t}\left(\theta^{t-1}, \theta_{t}\right)+q \cdot \mathbf{b}_{t+1}\left(\theta^{t}\right)+\Delta\left(\theta^{t-1}, \theta_{t}\right)=\mathbf{b}_{t}\left(\theta^{t-1}\right)+\Delta\left(\theta^{t-1}, \theta_{t}\right) .
$$

The quantities $\Delta(\cdot)$ represent potential insurance that an agent might receive. We next consider the self-insurance environment in the presence of this additional insurance. A formulation of (21) for an agent with history $\left(\theta^{t-1}, \theta_{t}\right)$, assets $\mathbf{b}_{t}$ and an additional insurance profile given by $\Delta(\cdot)$ available at time $t$ is given by: 


$$
\begin{aligned}
& W^{b s}\left(\theta^{t-1}, \theta_{t}\right)\left[\mathbf{b}_{t}\left(\theta^{t-1}\right)\right]= \\
& =\max _{\mathbf{b}_{t+1}\left(\theta^{t-1}, \theta_{t}\right), y(\theta)} u\left(\mathbf{b}_{t}\left(\theta^{t-1}\right)-\mathbf{b}_{t+1}\left(\theta^{t-1}, \theta_{t}\right)+\Delta\left(\theta_{t}\right)+y\left(\theta_{t}\right)\right)+ \\
& \quad-v\left(\frac{y\left(\theta_{t}\right)}{\theta_{t}}\right)+\beta \sum_{\theta \in \Theta} \pi(\theta) W^{b s}\left(\left(\theta^{t-1}, \theta_{t}\right), \theta\right)\left[\mathbf{b}_{t+1}\left(\theta^{t-1}, \theta_{t}\right)\right]
\end{aligned}
$$

We now look at the behavior of continuation utility in the above environment. As an example, consider two agents with current realizations $\theta_{t}$ and $\theta_{t}^{\prime}$ with $\theta_{t}>\theta_{t}^{\prime}$. Positive insurance requires that $\Delta\left(\theta_{t}^{\prime}\right)>\Delta\left(\theta_{t}\right)$. To simplify notation let $b\left(\theta^{t-1}, \theta_{t}\right)=\mathbf{b}_{t}\left(\theta^{t-1}\right)-\mathbf{b}_{t+1}\left(\theta_{t}\right)+\Delta\left(\theta_{t}\right)$ and $W^{\prime b s}\left(\theta^{t-1}, \theta_{t}\right)[x]=\sum_{\theta \in \Theta} \pi(\theta) W^{b s}\left(\left(\theta^{t-1}, \theta_{t}\right), \theta\right)\left[\mathbf{b}_{t+1}\left(\theta^{t-1}, \theta_{t}\right)+x\right]$. We then have:

$$
\begin{array}{r}
W^{\prime b s}\left(\theta^{t-1}, \theta_{t}^{\prime}\right)\left[b\left(\theta^{t-1}, \theta_{t}^{\prime}\right)-b\left(\theta^{t-1}, \theta_{t}\right)\right]= \\
=W^{\prime b s}\left(\theta^{t-1}, \theta\right)\left[\Delta\left(\theta_{t}^{\prime}\right)-\Delta\left(\theta_{t}\right)\right]>W^{\prime b s}\left(\theta^{t-1}, \theta\right) .
\end{array}
$$

Where the first equality holds due to the fact that continuation utility in a self-insurance environment depends only on the assets available to the agent (since labor is always chosen optimally and borrowing and saving is unrestricted). Also, the last inequality in (27) follows from the fact that positive insurance is being received across states $\theta_{t}^{\prime}$ and $\theta_{t}$. The above relationship implies that in the presence of positive insurance, the continuation utility of the agent of type $\theta_{t}^{\prime}$ is higher than the one of type $\theta_{t}$ if the $\theta_{t}^{\prime}$ agent saved the entire difference in current transfers received by the two types. This behavior of continuation utilities is in stark contrast to the requirement imposed on the equilibrium by Lemma 3. In particular, equation (18) requires that the opposite inequality must hold in an environment with non-exclusivity. This can only occur if at time $t$ and all $\theta_{t}$ we have $\Delta\left(\theta_{t}\right)=0$.

\section{Existence of equilibrium}

The previous section characterizes the necessary conditions that an equilibrium allocation must satisfy. The next Proposition shows that an equilibrium of a menu game exists. The proof is by construction: we first provide the strategies of the firms (the menus) that sustain the allocation characterized in the previous section as an equilibrium. We then show that no entrant can improve on the incumbent contract. In this section, we also show that an equilibrium fails to exist if firms are restricted to offer direct mechanisms.

Proposition 3. The allocation $\{\hat{b}, \hat{y}\}$ defined as the solution to $(21)$ is an equilibrium of the menu game.

Proof. In Appendix C.

In the proof of Proposition 3, we show that the equilibrium allocation $\{\hat{b}, \hat{y}\}$ can be supported by menus offered by at least two firms. The menus are comprised by simple linear contracts over the entire feasible range. The first menu (denoted by $C^{S}$ ) allows an agent to pick any positive amount of work and receive his marginal product. The second menu (denoted by $C^{D}$ ) allows an agent to borrow and save any amount (consistent on being able to repay it) at the interest rate $1 / q$. These menus have two roles to sustain the equilibrium. First, $C^{S}$ allows an agent to solve his static consumption-leisure optimization problem, and $C^{D}$ allows the agent to solve his dynamic optimization problem. Second, these linear contracts deter any deviation from entrant or 
incumbent. To prove the Proposition we proceed in two steps. In the fist step, we apply Lemma 3 and show that the net present value of transfers that an agent would receive by a deviating firm can only positively co-move with the current income realization. This implies that any deviation, if profitable, can only provide a form of negative insurance. In the second step, we show that a deviating firm offering negative insurance cannot improve the ex ante welfare of the agent, hence no agent will accept the contract offered by the deviating firm. The complete proof of Proposition 3 is provided in the Appendix.

To provide additional intuition on the proof, we show the result in a static case with two types of agents. Let $\Theta=\left\{\theta_{L}, \theta_{H}\right\}$ with $\theta_{L}<\theta_{H}$. Let $\pi$ the probability of drawing $\theta_{H}$. Since we are in a static environment, the incumbents $i \in\{1,2\}$ only offer the linear wage contract: $C^{S}=\{(0, \delta): \delta \geq 0\}$. With superscript $\star$ we denote the optimal allocations that an agent chooses

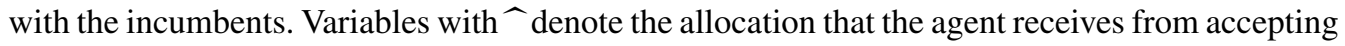
the entrant contract and potentially choosing additional contracts with the incumbents. Define

$$
\begin{array}{r}
\Delta=\pi\left[u\left(y_{H}^{\star}\right)-v\left(\frac{y_{H}^{\star}}{\theta_{H}}\right)\right]+(1-\pi)\left[u\left(y_{L}^{\star}\right)-v\left(\frac{y_{L}^{\star}}{\theta_{L}}\right)\right]+ \\
-\pi\left[u\left(\widehat{y}_{H}+\widehat{b}_{H}\right)-v\left(\frac{\widehat{y}_{H}}{\theta_{H}}\right)\right]-(1-\pi)\left[u\left(\widehat{y}_{L}+\widehat{b}_{L}\right)-v\left(\frac{\widehat{y}_{L}}{\theta_{L}}\right)\right] .
\end{array}
$$

$\Delta$ represents the difference in ex ante utility levels between the agent choosing contracts only with the incumbents and the utility level of choosing contracts with an entrant (together with any additional contract with the incumbents). The ultimate goal is now to show that $\Delta>0$. As a first step, we show a positive relationship between the type of the agent and the transfer received by the entrant. Since $\theta_{H}>\theta_{L}$, we have that $\widehat{y}_{H}>\widehat{y}_{L}$ (from the incentive compatibility conditions of the entrant's contract). As a direct application of Lemma 3 , we have that $\widehat{b}_{H} \geq \widehat{b}_{L}$.

We next show that the contract of the entrant is welfare reducing for the agent: $\Delta>0$. To see this, first note that within the contracts offered by the incumbent, $C^{S}$, it is always possible for the agents $i=L, H$ to choose $y_{i}^{\star}=\widehat{y}_{i}$. This implies that:

$$
\Delta \geq \pi u\left(\widehat{y}_{H}\right)+(1-\pi) u\left(\widehat{y}_{L}\right)-\pi u\left(\widehat{y}_{H}+\widehat{b}_{H}\right)-(1-\pi) u\left(\widehat{y}_{L}+\widehat{b}_{L}\right) .
$$

We then conclude by showing that the right hand side of (28) is strictly greater than zero. This is because the deviating incumbent generates strictly positive profits so that $\bar{b}=\pi \widehat{b}_{H}+(1-\pi) \widehat{b}_{L}<$ 0 ; in addition, from the previous step we have that $\widehat{b}_{H} \geq \widehat{b}_{L}$. Overall, the deviating contract constitutes a (mean decreasing) increasing spread in consumption.

Note that without latent contracts, the key result of Lemma 3 would not hold, so that it would be possible for the entrant to provide some positive insurance. An immediate implication of the existence result in Proposition 3 and the equivalence result in Proposition 2 is that the equilibrium is unique in terms of allocations. At the same time, there are multiple equilibrium strategies (of agents and firms) that can sustain the equilibrium.

\section{Corollary 1. There exists a unique equilibrium allocation of the menu game.}

In the equilibrium, it is necessary for at least two firms to offer the menus $C^{S}$ and $C^{D}$, which implies that some of the allocations offered are not chosen in equilibrium: they will be latent. Suppose only one of the firms is active in equilibrium. The allocation $\{\hat{b}, \hat{y}\}$ fails to be an equilibrium allocation since an entrant will deviate, offering a profitable welfare increasing menu, 
in the shape of a contingent contract. As an example, consider the following profitable deviation (motivated by Abraham and Pavoni, 2005) where in the last period the constrained efficient allocation is offered. Let $\left\{\tilde{b}\left(b^{-1}\right), \tilde{y}\left(b^{-1}\right)\right\}$ be the solution to the following problem:

$$
\begin{aligned}
& \tilde{U}\left(b^{-1}\right)=\max _{b, y} \sum_{\theta} \pi(\theta)\left[u\left(b_{t}(\theta)+y_{t}(\theta)\right)-\frac{1}{\theta} v\left(\frac{y_{t}(\theta)}{\theta}\right)\right], \\
& \text { s.t. } \quad u\left(b_{t}(\theta)+y_{t}(\theta)\right)-\frac{1}{\theta} v\left(\frac{y_{t}(\theta)}{\theta}\right) \geq u\left(b_{t}(\hat{\theta})+y_{t}(\hat{\theta})\right)-\frac{1}{\theta} v\left(\frac{y_{t}(\hat{\theta})}{\theta}\right), \\
& \qquad \sum_{\theta} \pi(\theta) b_{t}(\theta)=b^{-1} .
\end{aligned}
$$

Note that $\tilde{U}\left(b^{-1}\right)$ is strictly larger than the utility of autarky with $b^{-1}$ additional (possibly negative) resources. Firm $i=1$ can deviate from the proposed equilibrium substituting the time $T$ menus with

$$
\tilde{C}^{T}\left(b^{i, T-1}, y^{i, T-1}\right)=\left\{\left\{\tilde{b}\left(b_{T-1}^{i}-\varepsilon\right), \tilde{y}\left(b_{T-1}^{i}-\varepsilon\right)\right\} \mid \text { solves (29) and } \varepsilon>0\right\} .
$$

For $\varepsilon$ sufficiently small, the agent prefers this contract to the original, and, in addition, this deviation provides additional $\frac{\varepsilon}{q^{1-T}}$ profits. In the presence of the contracts $C^{S}$ and $C^{D}$ offered by firm $i=2$, the deviation (30) is unprofitable. This is because at time $T$ it implies positive net transfers from more productive to less productive agents. So, if a high productivity agent also has access to the static labor contract $C^{S}$, he would choose in (30) the allocation designed for the low productivity agent (collecting the positive transfers) and work the additional hours with the firm offering the latent contract $C^{S}$. This strictly improves the utility of the high productivity agent since he works the same amount of hours and receives higher consumption. This choice of the high-productivity agent makes the profits of the deviation (30) negative, since all agents choose the allocation with positive transfers.

\section{Infinite horizon}

In this section, we discuss the infinite horizon case. It is important to note that some key results described in Section 3.2 hold for any time horizon. First of all, this is the case for Lemma 1 and Lemma 2. These lemmas characterize the possible distortions that can arise in equilibrium both on the consumption-leisure margin (Lemma 1) and on the inter-temporal margin (Lemma 2). In addition, Lemma 3 also holds for any time horizon. This Lemma highlights how the nonexclusivity of contracts limits the amount of insurance that can be provided in equilibrium. In what follows we show how these results are sufficient to determine that under non-exclusive contracts the agent cannot do better than in the self-insurance equilibrium.

Remark 3. The presence of infinite horizon also introduces novel results not available for the finite horizon case. Lemma 2 implies that the process for marginal utility of consumption is a martingale. This property has been shown to provide powerful characterization results both in environment with private information and exclusive contracting (for example in Thomas and Worrall, 1990 and Atkeson and Lucas, 1992) as well as in environments with incomplete markets (for example in Chamberlain and Wilson, 2000). Define $f\left(\theta^{t}\right)=u^{\prime}\left(c_{t}\left(\theta^{t}\right)\right.$ ). Lemma 2 implies that the equilibrium allocation in the environment without exclusivity must satisfy the following 
relationship:

$$
f\left(\theta^{t}\right)=\frac{\beta}{q} \sum_{\theta_{t+1}} \pi\left(\theta_{t+1}\right) f\left(\theta^{t}, \theta_{t+1}\right), \quad \forall t, \theta^{t} .
$$

In the case in which $\beta \leq q$, the above implies that $f\left(\theta^{t}\right)$ is a sub-martingale. Once the environment features an infinite time horizon, from standard results (see Doob, 1953), it follows that the stochastic process must converge over time with probability one. This implies that $u^{\prime}\left(c_{t}\left(\theta^{t}\right)\right)$ converges to $u^{\prime}(c(\theta))$ over time. Although a similar result holds in environments with private information and exclusive contracting, the implication for our benchmark environment is different. In the environment with exclusive contracting, the incentive constraints and the convergence of marginal utility of consumption imply a front-loading of insurance and an eventual immiseration of the agent. In the environment without exclusive contracting, the convergence in the marginal utility of consumption implies convergence to full insurance due to an ever-greater accumulation of assets on the part of the agent (as in Chamberlain and Wilson, 2000).

The discussion of the previous sections establishes the self-insurance equilibrium as a natural candidate equilibrium for the infinite horizon case. ${ }^{17}$ For this candidate equilibrium, none of the contracts offered in order to sustain the self-insurance equilibrium requires any separation of types. Hence the payoff of an insurance provider offering this contract is immune to any entry. Our strategy is to use the self-insurance equilibrium as a benchmark for the time zero equilibrium utility level. Let $\bar{W}$ be the time zero utility level received by an agent in a borrowing saving equilibrium where the insurance provider makes zero profits. Let $W^{\star}$ be the time zero equilibrium utility level that agents receive. It is clear that $\bar{W} \leq W^{\star}$. If not, an entrant would offer a self-insurance contract delivering a utility level in the interval $\left(W^{\star}, \bar{W}\right)$. The next Proposition demonstrates that, in equilibrium, agents will receive a time zero payoff equal to $\bar{W}$.

Proposition 4. Any infinite horizon equilibrium allocation delivers a time zero equilibrium payoff to the agent equal to $W^{\star}=\bar{W}$.

Proof. In Appendix C.1.

\section{Conclusion}

A large fraction of the literature on optimal social insurance under private information features stark assumptions on the ability of agents to sign additional contracts. Agents are required to be either in exclusive relationships with an insurance provider or, at the very least, to sign contracts featuring an extreme level of cross-indexing. This cross-indexing (or interdependence of contracts) takes into account any other relationship the agent might engage, whether a labor, credit, or an insurance relationship. In many instances, the above assumptions are driven by analytic tractability rather than empirical motivation. Real-world contractual relationships rarely feature exclusivity clauses. Even more rare are instances of complete cross-indexing of contracts: for example, compensation being affected by the balance in a savings account.

This paper relaxes the exclusivity assumption taking the opposite, extreme view. In our environment, it is costless to engage in additional contractual relationships, and they are available

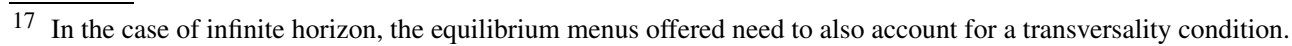


in every period. The implications of this alternative view are significant. Our main result is that competition reduces the amount of insurance provided: the equilibrium is equivalent to a selfinsurance economy. In this environment, the competition between insurance providers results in linear contracts being the only contracts offered in equilibrium. This is true in labor relationships, so that the wage always reflects the marginal product. It is also true for inter-temporal contracts, so that the rate of return on debt (or savings) is equal to the inter-temporal technical rate of transformation. Finally, in equilibrium there is no redistribution. We also show that an equilibrium exists in this environment and that latent contracts play an essential role. From a methodological standpoint this paper shows the applicability of menu games to the study of dynamic social insurance problems.

An interesting avenue for future research is to determine if it is possible to improve on selfinsurance by imposing some restrictions on the contracts offered in equilibrium while still maintaining non-exclusivity. A possible way to proceed is similar to the one described by Abraham and Pavoni (2008), discriminating between which contracts are exclusive (for example, labor relationships) and which are not (for example, credit relationships). Alternatively, consider an environment with an additional observable, potentially noisy, signal. The signal provides information on the contracts the agent is currently enrolled in. The case presented in the present paper can be considered as a case in which the signal carries no useful information: it is just noise. In this case, there is no cost if the agent signs any additional contract with entrants. The allocation arising from the standard environment with full exclusivity can also be replicated by this modified environment. It would be one in which the signal provides perfect information on the contracts signed by the agent. What is key is that an insurance provider can punish the agent whenever he defects. Given this is optimal for the agent to agree ex ante to severe punishment to prevent any ex-post deviation. In this case, although the environment features non-exclusivity, the option to deviate with an entrant is never exercised by the agent. An interesting case is an intermediate one: one in which the signal carries only imperfect information. Now a harsh punishment would be suboptimal as type-I errors would be present. However, some punishment would still be present so that the agent faces a cost of signing additional contracts. We conjecture that this in this type of environment it might be possible to sustain some insurance especially with respect to small risks.

The results of this paper have important implications for the analysis of positive questions. It provides a micro-foundation of standard incomplete market models based entirely on equilibrium competition. The absence of exclusive relationships results in stark differences in the allocation that arises versus an environment with complete exclusivity. These differences can be tested by looking at Data on consumption, income, and hours. The question is, then, which households are more likely to feature an allocation in line with an environment with non-exclusive competition?

\section{Appendix A. General communication and delegation principle}

In this appendix, we define a general communication mechanism and show that, in our environment, the equilibrium of a communication game can be implemented as an equilibrium of a menu game in which firms offer a menu of payoff-relevant alternatives, and the agents choose an allocation from it.

\section{Communication}

Firms and agents communicate according to a communication mechanism which consists, for each firm $i \in\{1, \ldots, I\}$, of a time 0 report space $\mathcal{R}^{i}$ and message spaces $\mathcal{M}_{t}^{i}$ for each 
$t \in\{1, \ldots, T\} .{ }^{18}$ The set of all possible messages that an agent can send to firm $i$ up to time $t$ is denoted by $\mathcal{M}^{i, t}=\mathcal{M}_{1}^{i} \times \ldots \times \mathcal{M}_{t}^{i}$. For a given message space, each firm chooses allocation functions $g_{t}^{i}: \mathcal{M}^{i, t} \rightarrow \mathbb{R} \times \mathbb{R}_{+}$, which specify net-transfers of consumption and output at time $t$. At time 0 , given the report space, a firm determines a contract $\phi^{i}: \mathcal{R}^{i} \rightarrow G_{1}^{i}\left(\mathcal{M}^{i, 1}\right) \times$ $\ldots \times G_{T}^{i}\left(\mathcal{M}^{i, T}\right)$, where $G_{t}^{i}\left(\mathcal{M}^{i, t}\right)$ is the set of all measurable mappings from message space $\mathcal{M}^{i, t}$ to the allocation space $\mathbb{R} \times \mathbb{R}_{+}$. The contract $\phi^{i}$ determines, conditional on the report $r^{i}$, the allocation functions an agent will have access to in all future periods. To shorten notation, let $G^{i}\left(\mathcal{M}^{i, T}\right) \equiv G_{1}^{i}\left(\mathcal{M}^{i, 1}\right) \times \ldots \times G_{T}^{i}\left(\mathcal{M}^{i, T}\right)$. Let $\Phi^{i}\left(\mathcal{R}^{i}, \mathcal{M}^{i, T}\right)$ be the set of all measurable mappings from reporting space $\mathcal{R}^{i}$ to the set $G^{i}\left(\mathcal{M}^{i, T}\right)$, and note that $\phi^{i} \in \Phi^{i}\left(\mathcal{R}^{i}, \mathcal{M}^{i, T}\right)$. Let $\mathcal{M}=\times_{i=1}^{I} \mathcal{M}^{i, T}$ and $\mathcal{R}=\times_{i=1}^{I} \mathcal{R}^{i}$. Denote the game associated with the communication mech$\operatorname{anism}(\mathcal{M}, \mathcal{R})$ by $\Gamma_{\mathcal{M}, \mathcal{R}}$.

At time 0 , before any uncertainty is realized, each firm $i$ simultaneously offers a collection of contracts $\phi^{i}$, and agents communicate with firms sending a message $r^{i}$. This message determines, through $\phi^{i}$, the functions $g_{t}^{i}$ at every subsequent period $t$. The timing of the game $\Gamma_{\mathcal{M}, \mathcal{R}}$ is the following:

- At time 0:

1. Each firm $i$ simultaneously offers contract $\phi^{i}: \mathcal{R}^{i} \rightarrow G^{i}\left(\mathcal{M}^{i, T}\right)$;

2. Agents send a report $r^{i} \in \mathcal{R}^{i}$ to each firm $i$.

- At time $1 \leq t \leq T$ :

1. Agent learns his private type $\theta_{t}$;

2. Firm offers allocation rule $g_{t}^{i}: \mathcal{M}^{i, t} \rightarrow \mathbb{R} \times \mathbb{R}_{+}$according to $\phi^{i}\left(r^{i}\right)$;

3. Agent sends a message $m_{t}^{i} \in \mathcal{M}_{t}^{i}$ to each firm $i$;

4. Payoffs are realized: output is produced and net-transfers are made.

Given messages $(\mathcal{M}, \mathcal{R})$, we consider a static Nash equilibrium played by firms at time 0 when choosing the contracts that are offered in future periods. Given these contracts, agents optimize choosing the report at time 0 and messages in every period $t=1, \ldots, T$.

Definition 2 (Equilibrium of communication game). A pure strategy equilibrium of $\Gamma_{\mathcal{M}, \mathcal{R}}$ is $\left(r^{*}, m^{*}, \phi^{*}, g^{*}\right)$ such that:

1. Agent's message $m_{t}^{*}: G_{t}^{1} \times \ldots \times G_{t}^{I} \times \Theta^{t} \rightarrow \mathcal{M}_{t}$ solves for each $t \in\{1, \ldots, T\}$ :

$$
\begin{aligned}
U_{t}\left(\theta_{t} \mid g^{*}, m^{t-1}\right)= & \max _{m_{t} \in \mathcal{M}_{t}} u\left(\sum_{i=1}^{I}\left(b^{i}\left(m^{i, t}\right)+y\left(m^{i, t}\right)\right)\right)-v\left(\frac{\sum_{i=1}^{I} y\left(m^{i, t}\right)}{\theta_{t}}\right)+ \\
& +\beta \sum_{\theta_{t+1}} \pi\left(\theta_{t+1}\right) U_{t+1}\left(\theta_{t+1} \mid g^{*}, m^{t}\right)
\end{aligned}
$$

subject to $\sum_{i=1}^{I}\left(b^{i}\left(m^{i, t}\right)+y\left(m^{i, t}\right)\right) \geq 0, \quad \sum_{i=1}^{I} y\left(m^{i, t}\right) \geq 0, \quad \forall t \quad$ where $\quad\left(b\left(m^{i, t}\right)\right.$, $\left.y\left(m^{i, t}\right)\right)=g_{t}^{*, i}\left(m^{i, t}\right)$ and $U_{T+1}(\cdot) \equiv 0$.

18 The environment studied in the body assumes free entry, hence the number I of firms that offer non-trivial contracts is determined in equilibrium. For simplicity in this section, we assume that this number is fixed. 
2. Agent's reporting strategy at time 0 : Let $g^{i}=\phi^{i, *}\left(r_{i}\right) . r^{*}: G^{1} \times \ldots \times G^{I} \rightarrow \mathcal{R}$ solves:

$$
\max _{r \in \mathcal{R}} \sum_{\theta_{1}} \pi\left(\theta_{1}\right) U_{1}\left(\theta_{1} \mid g\right)
$$

3. Taking as given the choices of the other firms and the agents' choices, for each firm $i \in$ $\{1, \ldots, I\}$, the contract $\phi^{i, *}$ solves:

$$
\begin{gathered}
V^{i}\left(\phi^{i, *}, \phi^{-i, *}\right) \equiv \min _{\phi^{i} \in G^{i}\left(\mathcal{M}^{i}\right)} \sum_{t=0}^{T} \sum_{\theta^{t}} \pi\left(\theta^{t}\right) q^{t} b_{t}^{i, *}\left(\theta^{t}\right), \\
b_{t}^{*}\left(\theta^{t}\right)=b\left(m^{t, *}\left(\theta^{t}\right)\right), g^{i}=\phi^{i}\left(r^{i, *}\right) \text { and } g^{-i, *}=\phi^{-i, *}\left(r^{-i, *}\right) .
\end{gathered}
$$

Denote the equilibrium allocation of a general communication game by $\left(b^{*}, y^{*}\right)$.

\section{Menu games}

To prove the equivalence between the equilibrium allocation of a given communication mechanism and the equilibrium of a menu game, it is essential that the menus offered are rich enough to capture the strategies used to implement equilibrium in a communication mechanism. In our environment, a menu is a sequence of sets, with each set being a subset of the allocation space $\mathbb{R} \times \mathbb{R}_{+}$. For a message space $(\mathcal{M}, \mathcal{R})$, define, for each firm $i$, the set $C_{t}^{i}\left(m^{i, t-1}, \mathcal{M}_{t}^{i} \mid G_{t}^{i}\right)$ as the menu that can be implemented by a message space $\mathcal{M}_{t}^{i}$ at time $t$ given a history of messages $m^{i, t-1}$ and a set of allocation functions $G_{t}^{i}$. Formally, a menu at time $t$ is the following set:

$$
C_{t}^{i}\left(m^{i, t-1}, \mathcal{M}_{t}^{i} \mid G_{t}^{i}\right) \equiv\left\{X \subseteq \mathbb{R} \times \mathbb{R}_{+} \mid \exists g_{t}^{i} \in G_{t}^{i} \subseteq G_{t}^{i}\left(\mathcal{M}^{i, t}\right): X=\operatorname{Im}\left(g_{t}^{i} \mid m^{i, t-1}\right)\right\} \quad \forall t, \forall i
$$

where

$$
\operatorname{Im}\left(g_{t}^{i} \mid m^{i, t-1}\right)=\left\{x \in \mathbb{R} \times \mathbb{R}_{+} \mid \exists m_{t}^{i} \in \mathcal{M}_{t}^{i}: x=g_{t}^{i}\left(m^{i, t-1}, m_{t}^{i}\right)\right\} \forall t, \forall i .
$$

Each set defined in (A.1) contains all subsets of $\mathbb{R} \times \mathbb{R}_{+}$with cardinality at most $\mathcal{M}_{t}^{i}$. For any subset $G_{t}^{i} \subseteq G_{t}^{i}\left(\mathcal{M}^{i, t}\right)$, let $G^{i} \equiv G_{1}^{i} \times \ldots \times G_{t}^{i}$ and define a sequence of menus offered by firms at time 0 as:

$$
C\left(G^{i}\right)=\left\{X_{t} \subseteq C_{t}^{i}\left(m^{i, t-1}, \mathcal{M}_{t}^{i} \mid G_{t}^{i}\right), t=1, \ldots, T, \forall m^{i, t-1} \in \mathcal{M}^{i, t-1}, m_{t}^{i} \in \mathcal{M}_{t}^{i}\right\} .
$$

At time 0 , each agent chooses a sequence of menus in the collection offered by firm $i$. Define $\mathcal{S}^{i}$ as the collection of menus that are consistent with a communication system $(\mathcal{M}, \mathcal{R})$.

$$
\mathcal{S}^{i}\left(\mathcal{R}^{i}, \mathcal{M}^{i}\right) \equiv\left\{C^{i} \subseteq C\left(G^{i}\right) \mid \exists \phi^{i} \in \Phi^{i}\left(\mathcal{R}^{i}, \mathcal{M}^{i}\right): G^{i}=\operatorname{Im}\left(\phi^{i}\right)\right\} .
$$

This set contains all the collections of sets $C^{i}$ with cardinality less than or equal to the cardinality of $\mathcal{R}^{i}$. Without explicitly writing the dependence on the message spaces, let $\mathcal{S}^{i}=\mathcal{C}^{i}\left(\mathcal{R}^{i}, \mathcal{M}^{i}\right)$ be the menus offered by firm $i$, and let $C^{i}$ be an element of $\mathcal{S}^{i}$. Let $\Gamma_{C, \mathcal{S}}$ be the game associated with menus $(C, \mathcal{S})$.

The following Proposition shows that an equilibrium in a general communication system can be implemented as an equilibrium of a menu game. In this menu game, the collection of menus offered by each firm must be compatible with the general communication mechanism as defined above. 
Proposition 5 (Delegation principle). Let $\left(b^{*}, y^{*}\right)$ be an equilibrium allocation of a general

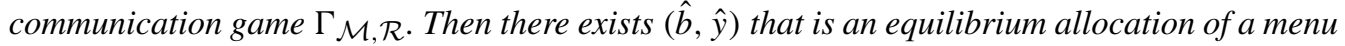
game $\Gamma_{C, \mathcal{S}}$ and $\left(b^{*}, y^{*}\right)=(\hat{b}, \hat{y})$.

Proof. The proof is by construction. Starting from the equilibrium strategies of a general communication game, we construct strategies for a menu game and show that these strategies constitute an equilibrium. Define as in (A.1) and (A.4) respectively the menus and the collection of menus that are compatible with message spaces $(\mathcal{M}, \mathcal{R})$. Define the strategy of firm $i$ in this menu game as:

$$
\hat{\mathcal{S}}^{i}=\left\{C^{i} \subseteq C^{i}\left(G^{i}\right) \mid G^{i}=\mathbf{I m}\left(\phi^{i, *}\right)\right\}
$$

The collection of menus $\hat{\mathcal{S}}^{i}$ contains all the subsets of the allocation space that are consistent with the collection of allocation functions in the original equilibrium. Agents' strategies are defined as follows: $\hat{C}^{i}=\left\{\hat{C}_{t}^{i} \in \hat{\mathcal{S}}^{i}: \hat{C}_{t}^{i}=\mathbf{I m}\left(g_{t}^{i, *} \mid m^{i, t-1, *}\right)\right.$ and $\left.g_{t}^{i, *}=\phi^{i, *}\left(r^{i, *}\right)\right\}$ and $\left(\hat{b}^{i}\left(\theta^{t}\right), \hat{y}^{i}\left(\theta^{t}\right)\right)=$ $g_{t}^{i, *}\left(m^{i, t, *}\left(\theta^{t}\right)\right)$. By construction $\hat{C}_{t}^{i} \in \hat{\mathcal{S}}^{i}$ and $\left(\hat{b}^{i}\left(\theta^{t}\right), \hat{y}^{i}\left(\theta^{t}\right)\right) \in \hat{C}_{t}^{i}, \forall \theta^{t}, \forall t$. The menu $\hat{C}_{t}^{i}$ is the subset of allocation space, $\mathbb{R}^{2}$, that corresponds to the allocation function chosen by the agent in the original equilibrium. Also $\left(\hat{b}^{i}, \hat{y}^{i}\right)$ corresponds to allocation determined by the allocation function given the equilibrium message sent by each type $\theta^{t}$. If agents and firms follow these strategies, the equilibrium allocation in the menu game is the same as in the original equilibrium.

First, let's show that the agents' strategies are an equilibrium. Suppose that at some time $t$, for some firm $i \exists\left(b_{t}^{i}, y_{t}^{i}\right) \in \hat{C}_{t}^{i}$ such that:

$$
\begin{aligned}
& u\left(\sum_{i=1}^{I}\left(b_{t}^{i}+y_{t}^{i}\right)\right)-v\left(\frac{\sum_{i=1}^{I} y_{t}^{i}}{\theta_{t}}\right)+\beta \sum_{\theta_{t+1}} \pi\left(\theta_{t+1}\right) U_{t+1}\left(\hat{b}^{t-1}, b_{t}, \hat{y}^{t-1}, y_{t}, \theta_{t+1} \mid \hat{C}\right)> \\
& u\left(\sum_{i=1}^{I}\left(\hat{b}_{t}^{i}+\hat{y}_{t}^{i}\right)\right)-v\left(\frac{\sum_{i=1}^{I} \hat{y}_{t}^{i}}{\theta_{t}}\right)+\beta \sum_{\theta_{t+1}} \pi\left(\theta_{t+1}\right) U_{t+1}\left(\hat{b}^{t}, \hat{y}^{t}, \theta_{t+1} \mid \hat{C}\right) .
\end{aligned}
$$

Since $\left(b_{t}^{i}, y_{t}^{i}\right) \in \hat{C}_{t}^{i}$, there exists $m_{t}^{i} \in \mathcal{M}_{t}^{i}$ such that $\left(b_{t}^{i}, y_{t}^{i}\right)=g_{t}^{i, *}\left(m^{i, t}\right)$. Replacing in the agents' payoff:

$$
\begin{aligned}
& u\left(\sum_{i=1}^{I}\left(b^{i}\left(m^{i, t}\right)+y\left(m^{i, t}\right)\right)\right)-v\left(\frac{\sum_{i=1}^{I} y\left(m^{i, t}\right)}{\theta_{t}}\right)+\beta \sum_{\theta_{t+1}} \pi\left(\theta_{t+1}\right) U_{t+1}\left(m^{t}, \theta_{t+1} \mid g^{*}\right)> \\
& u\left(\sum_{i=1}^{I}\left(b^{i}\left(m^{i, t, *}\right)+y\left(m^{i, t, *}\right)\right)\right)-v\left(\frac{\sum_{i=1}^{I} y\left(m^{i, t, *}\right)}{\theta_{t}}\right)+ \\
& \quad+\beta \sum_{\theta_{t+1}} \pi\left(\theta_{t+1}\right) U_{t+1}\left(m^{t, *}, \theta_{t+1} \mid g^{*}\right) .
\end{aligned}
$$

But this contradicts $m^{i, *}$ being an equilibrium in the original game. Now suppose $\hat{C}^{i}$ is not an equilibrium for some $i$. There exists some $C^{i} \in \hat{\mathcal{S}}^{i}$ such that: $U\left(C^{i}, \hat{C}_{-i}\right)>U(\hat{C})$. Since $C^{i} \in \hat{\mathcal{S}}^{i}, \exists r^{i} \in \mathcal{R}^{i}$ such that $C^{i}=\mathbf{I m}\left(g^{i}\right)$ and $g^{i}=\phi^{i, *}\left(r^{i}\right)$. Replacing in the agents' payoff: $U\left(g^{i}, g_{-i}^{*},\right)>U\left(g^{i, *}, g_{-i}^{*}\right)$. But this contradicts $r^{i, *}$ being an equilibrium in the original game. Finally, we check that firms' strategies constitute an equilibrium. Suppose $\exists \mathcal{S}^{i} \in \mathcal{S}^{i}\left(\mathcal{R}^{i}, \mathcal{M}^{i}\right)$ such that $V^{i}\left(\mathcal{S}^{i}, \hat{\mathcal{S}}^{-i}\right)>V^{i}\left(\hat{\mathcal{S}}^{i}, \hat{\mathcal{S}}^{-i}\right)$. Since $\mathcal{S}^{i} \in \mathcal{S}^{i}\left(\mathcal{R}^{i}, \mathcal{M}^{i}\right)$, there exists $\phi^{i}$ such that $g^{i}=$ 
$\phi^{i}\left(r^{i, *}\right)$. Replacing in the firm's payoff in the original game $V^{i}\left(\phi^{i}, \phi_{-i}^{*}\right)>V^{i}\left(\phi^{i, *}, \phi_{-i}^{*}\right)$. But this contradicts $\phi^{i, *}$ being an equilibrium in the original game.

Similarly to Martimort and Stole (2002), Proposition 5 states that for a given message spaces $(\mathcal{M}, \mathcal{R})$, there exists a menu game that implements the same equilibrium allocation. It is important to note that message spaces restrict the menus that can be offered in a menu game. Hence, if firms are allowed to use unrestricted message spaces, the same equilibrium allocation can be implemented if firms can offer unrestricted menus.

\section{Appendix B. Proofs of Section 3}

\section{B.1. Proof of Lemma 2}

Proof. Suppose by contradiction that for some history $\widehat{\theta}^{t}$ equation (16) does not hold. As a first case suppose that:

$$
u^{\prime}\left(c_{t}\left(\widehat{\theta}^{t}\right)\right)>\frac{\beta}{q} \sum_{\theta_{t+1}} \pi\left(\theta_{t+1}\right) u^{\prime}\left(c_{t+1}\left(\widehat{\theta}^{t}, \theta_{t+1}\right)\right) .
$$

In this case, the agent is borrowing constrained. An entrant can make strictly positive profits offering a borrowing contract at a rate higher than $1 / q$, contradicting the original allocation being an equilibrium. The first step is to construct the contract to be offered by a firm. Let $\varepsilon>0$ and small, define $\delta^{*}(\varepsilon)$ as the solution of the following problem:

$$
\max _{\delta \geq 0} u\left(c_{t}\left(\widehat{\theta}^{t}\right)+\delta\right)+\beta E_{t} u\left(c_{t+1}\left(\widehat{\theta}^{t}, \theta_{t+1}\right)-\delta \cdot\left(\frac{1}{q}+\varepsilon\right)\right) .
$$

This problem can be interpreted as the optimal borrowing problem (choosing $\delta$ ) when the interest rate is given by $1 / q+\varepsilon$. The first order condition for this problem is:

$$
u^{\prime}\left(c_{t}\left(\widehat{\theta}^{t}\right)+\delta\right) \leq \beta\left(\frac{1}{q}+\varepsilon\right) E_{t} u^{\prime}\left(c_{t+1}\left(\widehat{\theta}^{t}, \theta_{t+1}\right)-\delta \cdot\left(\frac{1}{q}+\varepsilon\right)\right) .
$$

Since (B.1) holds, if $\varepsilon=0$, the solution for the above problem features $\delta^{*}(0)>0$. From the Theorem of the Maximum, the function $\delta^{*}(\cdot)$ is continuous. This implies there exists an $\varepsilon>0$ and sufficiently small so that $\delta^{*}(\varepsilon)>0$. Consider an entrant that offers a menu at time $t$ equal to $\widehat{C}_{t}=\left\{\left(\delta^{*}(\varepsilon), 0\right),(0,0)\right\}$ and at time $t+1$ offers $\widehat{C}_{t+1}\left(\left(\delta^{*}(\varepsilon), 0\right)\right)=\left(-\delta^{*}(\varepsilon)\left(\frac{1}{q}+\varepsilon\right), 0\right)$ and $\widehat{C}_{t+1}((0,0))=(0,0)$. For all other periods and histories the entrant offers a menu only containing the contract $(0,0)$. The entrant makes strictly positive profits, proportional to $\delta^{*}(\varepsilon) \varepsilon$, and the agent is strictly better off keeping the original equilibrium together with this contract since it increases his utility in a history with positive probability and keeps the same utility in all other histories. Since we have found a profitable deviation, we reach a contradiction.

In the remaining case, the agent is saving constrained: $u^{\prime}\left(c_{t}\left(\widehat{\theta}^{t}\right)\right)<\frac{\beta}{q} \sum_{\theta_{t+1}} u^{\prime}\left(c_{t+1}\left(\widehat{\theta}^{t}\right.\right.$, $\left.\left.\theta_{t+1}\right)\right) \pi\left(\theta_{t+1}\right)$. This case can be proved using a similar argument as in the proof of (B.1).

\section{B.2. Proof of Proposition 1}

Before proving Proposition 1, we introduce an additional Lemma. For ease of exposition in this section we assume that the equilibrium allocation is provided by a single incumbent firm. The 
proof extends to the case in which the equilibrium allocation is provided by multiple incumbents. Let $b_{t}\left(\theta^{t}\right)$ be the transfer that an agent with history $\theta^{t}$ receives at time $t$. Define the net present value of transfers received from time $t$ (included) onwards $\mathbf{b}_{t}\left(\theta^{t-1}\right)$ as in (25). Given a history $\theta^{t-1}$ and a realization $\theta_{t}$, expected transfers at time $t<T$ are given by:

$$
A_{t}\left(\theta^{t-1}, \theta_{t}\right)=b_{t}\left(\theta^{t-1}, \theta_{t}\right)+q \cdot \mathbf{b}_{t+1}\left(\theta^{t}\right) .
$$

And $A_{T}\left(\theta^{T-1}, \theta_{T}\right) \equiv b_{T}\left(\theta^{T-1}, \theta_{T}\right)$ for all $\theta^{T-1}, \theta_{T}$. In the following Lemma, we show that if expected future transfers do not depend on $\theta_{t}$, then there is no distortion on the consumptionleisure margin.

Lemma 4. Suppose that at time $t$ for some history $\theta^{t-1}, A_{t}\left(\theta^{t-1}, \theta_{t}\right)=A_{t}\left(\theta^{t-1}, \theta_{t}^{\prime}\right)$ for all $\theta_{t}, \theta_{t}^{\prime} \in \Theta$. Then for all $\theta_{t} \in \Theta$ we have:

$$
u^{\prime}\left(b_{t}\left(\theta^{t-1}, \theta_{t}\right)+y_{t}\left(\theta^{t-1}, \theta_{t}\right)\right)=v^{\prime}\left(\frac{y_{t}\left(\theta^{t-1}, \theta_{t}\right)}{\theta_{t}}\right) \frac{1}{\theta_{t}} .
$$

Proof. Suppose that for some $\theta^{t-1}$ there exists a $\theta_{t}$ for which equation (B.4) does not hold. From Lemma 1, there is only one case left to consider:

$$
u^{\prime}\left(b_{t}\left(\theta^{t}\right)+y_{t}\left(\theta^{t}\right)\right)<v^{\prime}\left(\frac{y_{t}\left(\theta^{t}\right)}{\theta_{t}}\right) \frac{1}{\theta_{t}} .
$$

Consider the following deviation of the incumbent: for all $1 \leq s<t$ the incumbent offers the original contract; at time $t$, the incumbent offers:

$$
\begin{aligned}
& \widetilde{C}_{t}\left(b_{t-1}\left(\theta^{t-1}\right), y_{t-1}\left(\theta^{t-1}\right)\right)= \\
& \left\{\left(b_{t}\left(\theta^{t-1}, \theta_{t}\right)-\varepsilon, y_{t}\left(\theta^{t-1}, \theta_{t}\right)+\delta\right) ;\left(b_{t}\left(\theta^{t-1}, \theta_{t}^{\prime}\right), y_{t}\left(\theta^{t-1}, \theta_{t}^{\prime}\right)\right), \forall \theta_{t}^{\prime} \neq \theta_{t}\right\} .
\end{aligned}
$$

Where $\delta$ and $\varepsilon$ are constructed as in the proof of Lemma 1, with the constraint $\delta \leq 0$. There exists $\varepsilon>0$ so that agent's $\theta_{t}$ utility is unchanged following this deviation. Given that $A_{t}\left(\theta^{t-1}, \theta_{t}\right)=$ $A_{t}\left(\theta^{t-1}, \theta_{t}^{\prime}\right)$ by assumption, deviations at time $t$ do not impact profits. We now look at deviations at time $t-1$. If no changes in the amount of resources borrowed/saved at time $t-1$ occurs, no deviations occurs at time $t-1$ since continuation payoff are left unchanged by the perturbation. However, a deviation at time $t-1$ does not occur due to the fact that saving was chosen optimally prior to the deviation (due to Lemma 2) and following standard envelope arguments (see, Milgrom and Segal, 2002).

We can now go to the proof of Proposition 1.

Proof. As a first step it is shown, by backward induction, that for all $t$ and all $\theta^{t-1}, A_{t}\left(\theta^{t-1}, \theta_{t}\right)$ is independent of $\theta_{t}$, formally:

$$
\forall t, \theta^{t-1}, \quad A_{t}\left(\theta^{t-1}, \theta_{t}\right)=A_{t}\left(\theta^{t-1}, \theta_{t}^{\prime}\right), \quad \forall \theta_{t}, \theta_{t}^{\prime} \in \Theta .
$$

The above result implies that $A\left(\theta_{1}\right)$ is the same for all $\theta_{1} \in \Theta$. Let $\bar{A} \equiv A\left(\theta_{1}\right)$. If $\bar{A}>0$, firms make strictly negative profits in equilibrium and are better off offering a null contract. If $\bar{A}<0$, firms make strictly positive profits in equilibrium. In this case, an entrant can offer the same sequence of transfers, giving an additional transfer $\varepsilon>0$ in the terminal period for all $\theta_{T}$. Since 
the sequence of transfers is not contingent on any history $\theta^{T}$, there is no latent contract that makes it unprofitable. Given that future expected transfers are constant across realizations and $\bar{A}=0$, we have that condition (19) in Proposition 1 holds. We first show that (B.5) holds at time $t=T$; then assuming it holds for all times $s$ such that $t<s<T$ we show that (B.5) holds at time $t$.

We proceed by backward induction. Suppose that at time $T$ equation (B.5) does not hold. Let $\underline{\theta}_{T}=\arg \min _{\theta \in \Theta} A_{T}\left(\theta^{T-1}, \theta\right)$ and $\bar{\theta}_{T}=\arg \max _{\theta \in \Theta} A_{T}\left(\theta^{T-1}, \theta\right)$. From the contradicting assumption, we have that $A_{T}\left(\theta^{T-1}, \underline{\theta}_{T}\right)=b_{T}\left(\theta^{T-1}, \underline{\theta}_{T}\right)<A_{T}\left(\theta^{T-1}, \bar{\theta}_{T}\right)=b_{T}\left(\theta^{T-1}, \bar{\theta}_{T}\right)$. From Lemma 3 it follows that $y_{T}\left(\theta^{T-1}, \underline{\theta}_{T}\right)<y_{T}\left(\theta^{T-1}, \bar{\theta}_{T}\right) .{ }^{19}$ Given this, consumption of agent of type $\underline{\theta}_{T}$ is strictly less than the consumption for agent $\bar{\theta}_{T}$. Consider the following deviation (denoted by $\sim$ ) of the incumbent. At time $T$ set: $\widetilde{b}_{T}\left(\theta^{T-1}, \underline{\theta}_{T}\right)=b_{T}\left(\theta^{T-1}, \underline{\theta}_{T}\right)+\delta(\varepsilon)$ and $\widetilde{b}_{T}\left(\theta^{T-1}, \bar{\theta}_{T}\right)=b_{T}\left(\theta^{T-1}, \bar{\theta}_{T}\right)-\varepsilon$ for $\varepsilon>0$ and arbitrarily small. For a given $\varepsilon>0, \delta(\varepsilon)$ is chosen so that expected utility is left unchanged (from here onwards we suppress previous histories):

$$
\begin{aligned}
& \pi(\underline{\theta})\left[u\left(b_{T}(\underline{\theta})+y_{T}(\underline{\theta})\right)-u\left(b_{T}(\underline{\theta})+\delta(\varepsilon)+y_{T}(\underline{\theta})\right)\right]+ \\
& +\pi(\bar{\theta})\left[u\left(b_{T}(\bar{\theta})+y_{T}(\bar{\theta})\right)-u\left(b_{T}(\bar{\theta})-\varepsilon+y_{T}(\bar{\theta})\right)\right]=0,
\end{aligned}
$$

which implies:

$$
\pi(\underline{\theta}) u^{\prime}\left(b_{T}(\underline{\theta})+y_{T}(\underline{\theta})\right) \delta(\varepsilon)=\pi(\bar{\theta}) u^{\prime}\left(b_{T}(\bar{\theta})+y_{T}(\bar{\theta})\right) \varepsilon .
$$

Since the consumption for agent $\bar{\theta}$ is greater than the one for $\underline{\theta}$, it follows that $\varepsilon>\delta$. In the ${ }^{\sim}$ deviation all other allocations are left unchanged. If no agent alters his behavior, profits are increased by a factor proportional to $\varepsilon-\delta$. We now look at deviations. Given the definition of $\underline{\theta}_{T}$, deviations at time $T$ are not a concern. We now look at deviations at time $T-1$. If no changes in the amount of resources borrowed/saved at time $T-1$ occurs, no deviations occurs at time $T-1$ since continuation payoff are left unchanged by the perturbation. We now show that no agent has any incentive to jointly borrow/save and deviate. To show this, for simplicity we focus on the utility deriving from consumption of an agent with history $\theta^{T-1}$, and show how it is affected by the above perturbation (to simplify, assume $\beta=q=1$ and $\Theta=\{\bar{\theta}, \underline{\theta}\}$ ). Define:

$$
\begin{aligned}
\widehat{W}_{c}(\varepsilon)= & \max _{s} u\left(b_{T-1}-s+y_{T-1}\right)+ \\
& +\left[\pi(\bar{\theta}) u\left(b_{T}(\bar{\theta})-\varepsilon+s+y_{T}(\bar{\theta})\right)+\pi(\underline{\theta}) u\left(b_{T}(\underline{\theta})+\delta(\varepsilon)+s+y_{T}(\underline{\theta})\right)\right] .
\end{aligned}
$$

From (B.6), we have that $\delta(0)=0$. From Lemma 2, we then have that $s$ is equal to zero for agent $\theta^{T-1}$ so that the payoff to agent $\theta^{t-1}$ is unchanged relative to the original equilibrium. We can now apply the envelope theorem (see, Milgrom and Segal, 2002) and we get $\widehat{W}_{c}^{\prime}(0)=$ $\left[-\pi(\bar{\theta}) u^{\prime}\left(b_{T}(\bar{\theta})+y_{T}(\bar{\theta})\right)+\pi(\underline{\theta}) u^{\prime}\left(b_{T}(\underline{\theta})+y_{T}(\underline{\theta})\right) \delta^{\prime}(0)\right]=0$, where the last inequality follows from totally differentiating (B.6) so that:

$$
\delta^{\prime}(0)=\frac{\pi(\bar{\theta}) u^{\prime}\left(b_{T}(\bar{\theta})+y_{T}(\bar{\theta})\right)}{\pi(\underline{\theta}) u^{\prime}\left(b_{T}(\underline{\theta})+y_{T}(\underline{\theta})\right)} .
$$

$\overline{19}$ Suppose this was not the case so that: $y_{T}\left(\theta^{T-1}, \underline{\theta}_{T}\right) \geq y_{T}\left(\theta^{T-1}, \bar{\theta}_{T}\right)$. Applying (17) in the case $t=T$ implies $b_{T}\left(\theta^{T-1}, \underline{\theta}_{T}\right) \geq b_{T}\left(\theta^{T-1}, \bar{\theta}_{T}\right)$ reaching a contradiction. 
This implies that in equilibrium a change at time $T$ that leaves the continuation utility unchanged will have no impact on the utility at time $T-1$ for agents of type $\theta^{T-1} .^{20}$

Having found a profitable deviation it must be the case that for all $\theta, \theta^{\prime}$ and $\theta^{T-1}$ we have $A_{T}\left(\theta^{T-1}, \theta\right)=A_{T}\left(\theta^{T-1}, \theta^{\prime}\right)$. Note that as a consequence of this, given Lemma 4 , we have that (B.4) holds for all types at time $T$.

We now assume that (B.5) holds for all periods between $T$ and $t+1$ and show that it holds for period $t$. Suppose condition (B.5) is violated at time $t$. As before, let $\underline{\theta}_{t}=\arg \min _{\theta \in \Theta} A_{t}\left(\theta^{t-1}, \theta\right)$ and $\bar{\theta}_{t}=\arg \max _{\theta \in \Theta} A_{t}\left(\theta^{t-1}, \theta\right)$. From the definition of $A_{t}$ in (B.3), we have that:

$$
\underbrace{b_{t}\left(\theta^{t-1}, \bar{\theta}_{t}\right)+q \cdot \mathbf{b}_{t+1}\left(\theta^{t-1}, \bar{\theta}_{t}\right)}_{A_{t}\left(\theta^{t-1}, \bar{\theta}_{t}\right)}>\underbrace{b_{t}\left(\theta^{t-1}, \underline{\theta}_{t}\right)+q \cdot \mathbf{b}_{t+1}\left(\theta^{t-1}, \underline{\theta}_{t}\right)}_{A_{t}\left(\theta^{t-1}, \underline{\theta}_{t}\right)}
$$

From the inductive assumption and from Lemma 4, agents face no intra-temporal distortions from time $t+1$ (included) onwards. Lemma 2 guarantees that the Euler equations holds from time $t+1$ (included) onwards. This implies that the equilibrium allocation from time $t+1$ onwards is equivalent to a self-insurance economy (see (21) for a formal definition). Let $S_{t+1}(x)$ be the utility the agent receives from entering time $t+1$ with a net present value of assets equal to $x$. For all $t$, the value function $S_{t+1}$ is monotonically increasing and strictly concave. From Lemma 3, it must be the case that $y_{t}\left(\theta^{t-1}, \bar{\theta}_{t}\right)>y_{t}\left(\theta^{t-1}, \underline{\theta}_{t}\right)$. Suppose not. Applying (18) of Lemma 3 we get:

$$
\begin{aligned}
& W_{t}\left(\theta^{t-1}, \underline{\theta}_{t}\right)=S_{t+1}\left(\mathbf{b}_{t+1}\left(\theta^{t-1}, \underline{\theta}_{t}\right)\right) \geq \\
& \geq S_{t+1}\left(\mathbf{b}_{t+1}\left(\theta^{t-1}, \bar{\theta}_{t}\right)+\frac{1}{q}\left(b_{t}\left(\theta^{t-1}, \bar{\theta}\right)-b_{t}\left(\theta^{t-1}, \underline{\theta}\right)\right)\right)=W_{t}\left(\theta^{t-1}, \bar{\theta}_{t}\right)
\end{aligned}
$$

Since $S_{t+1}$ is strictly increasing, we reach a contradiction with (B.7). We next consider two cases. First the case with $b_{t}\left(\bar{\theta}_{t}\right)+y_{t}\left(\bar{\theta}_{t}\right)>b_{t}\left(\underline{\theta}_{t}\right)+y_{t}\left(\underline{\theta}_{t}\right)$. Proceeding similarly to the time $T$ case, consider a deviation of the incumbent (denoted with $\sim$ ) in which $\widetilde{b}_{t}\left(\bar{\theta}_{t}\right)=b_{t}\left(\bar{\theta}_{t}\right)-\varepsilon$ and $\widetilde{b}_{t}\left(\underline{\theta}_{t}\right)=b_{t}\left(\underline{\theta}_{t}\right)+\delta$. With $\varepsilon>0$ and small and $\delta$ chosen so that the expected utility at time $t$ is left unchanged. If no agent alters his behavior, profits are increased by a factor proportional to $\varepsilon-\delta$. We now look at deviations at time $t$ and $t-1$. Given the definition of $\underline{\theta}_{t}$, deviations at time $t$ are not a concern. As in the previous case, the envelope argument assures that no deviation take place at time $t-1$. The last case to consider is the case $b_{t}\left(\bar{\theta}_{t}\right)+y_{t}\left(\bar{\theta}_{t}\right) \leq b_{t}\left(\underline{\theta}_{t}\right)+y_{t}\left(\underline{\theta}_{t}\right)$. Since $y_{t}\left(\theta^{t-1}, \bar{\theta}_{t}\right)>y_{t}\left(\theta^{t-1}, \underline{\theta}_{t}\right)$, this implies $b_{t}\left(\underline{\theta}_{t}\right)<b_{t}\left(\bar{\theta}_{t}\right)$ so that $\mathbf{b}_{t+1}\left(\theta^{t-1}, \bar{\theta}_{t}\right)>\mathbf{b}_{t+1}\left(\theta^{t-1}, \underline{\theta}_{t}\right)$. A contradiction is then reached using the strict concavity of $S_{t+1}$ and Lemma 2. From Lemma 4, we then have that condition (20) holds in every period $1, \ldots, T$. This completes the proof of Proposition 1.

\section{Appendix C. Proof of Proposition 3}

Proof. The proof is by construction, and it is divided in two steps. In the first step, we describe the menus offered by incumbent firms and show that agents optimally choose the allocation $\{\hat{b}, \hat{y}\}$ as an equilibrium. In the second step, we show that no firm has an incentive to deviate from the proposed equilibrium.

20 It should be noted that similar arguments also hold for agents with history $\left(\theta^{T-2}, \theta^{\prime}\right)$ with $\theta^{\prime} \neq \theta_{T-1}$ that would otherwise deviate following the perturbation at time $T$. 


\section{Step 1}

Assume that firms $i \notin\{1,2\}$ offer only the null contract; firms $i \in\{1,2\}$ offer two menus: a "dynamic contract" and a "static contract." The dynamic contract is defined for all $t=1, \ldots, T$ as follows:

$$
C_{t}^{D}\left(b_{t-1}^{i}, y_{t-1}^{i}\right)=\left\{\left(b_{t}^{i}, 0\right): b_{t}^{i} \in \mathbb{R}, \mid b_{t}^{i}=\frac{1}{q} b_{t-1}^{i}+x_{t}, b_{T}^{i}=b_{0}^{i}=0, x_{t} \in \mathbb{R}\right\} .
$$

The static contract for all $t=1, \ldots, T$ is given by:

$$
C_{t}^{S}=\{(0, \delta): \delta \geq 0\} .
$$

Both menus generate zero profit for any choice of the agents. Given these menus, without loss of generality, at time zero the agents choose menu $C^{D}$ and $C^{S}$ from both firms $i \in\{1,2\}$. For $t>0$, we derive the agents' choices by backward induction. At time $T$, an agent with history $\left(\theta^{T-1}, \theta_{T}\right)$ and past choices $\left(\tilde{b}_{T-1}\left(\theta^{T-1}\right), \tilde{y}_{T-1}\left(\theta^{T-1}\right)\right)$ chooses from menu $C_{T}^{D}\left(\tilde{b}_{T-1}^{i}\left(\theta^{T-1}\right), \tilde{y}_{T-1}^{i}\left(\theta^{T-1}\right)\right)$ and menu $C_{T}^{S}$ the allocation $\left(\tilde{b}_{T}^{i}\left(\theta^{T}\right), \tilde{y}_{T}^{i}\left(\theta^{T}\right)\right)$ such that:

$$
u^{\prime}\left(-\frac{1}{q} \tilde{b}_{T}^{i}\left(\theta^{T-1}\right)+\tilde{y}_{T}^{i}\left(\theta^{T}\right)\right)=\frac{1}{\theta_{T}} v^{\prime}\left(\frac{\tilde{y}_{T}^{i}\left(\theta^{T}\right)}{\theta_{T}}\right) .
$$

For time $t \in\{1, \ldots, T-1\}$, an agent with history $\theta^{t}$ and past choices $\left(\tilde{b}_{t-1}^{i}\left(\theta^{t-1}\right), \tilde{y}_{t-1}^{i}\left(\theta^{t-1}\right)\right)$ chooses from menu $C_{t}^{D}\left(\tilde{b}_{t-1}^{i}\left(\theta^{t-1}\right), \tilde{y}_{t-1}^{i}\left(\theta^{t-1}\right)\right)$ and $C_{t}^{S}$ allocation $\left(\tilde{b}_{t}^{i}\left(\theta^{t}\right), \tilde{y}_{t}^{i}\left(\theta^{t}\right)\right)$ such that

$$
\begin{aligned}
& u^{\prime}\left(-\frac{1}{q} \tilde{b}_{t}^{i}\left(\theta^{t-1}\right)+\tilde{b}_{t}^{i}\left(\theta^{t}\right)+\tilde{y}_{t}^{i}\left(\theta^{t}\right)\right)=\frac{\beta}{q} \mathbb{E}_{t}\left[u^{\prime}\left(-\frac{1}{q} \tilde{b}_{t}^{i}\left(\theta^{t}\right)+\tilde{b}_{t}^{i}\left(\theta^{t+1}\right)+\tilde{y}_{t}^{i}\left(\theta^{t+1}\right)\right)\right], \\
& u^{\prime}\left(-\frac{1}{q} \tilde{b}_{t}^{i}\left(\theta^{t-1}\right)+\tilde{b}_{t}^{i}\left(\theta^{t}\right)+\tilde{y}_{t}^{i}\left(\theta^{t}\right)\right)=\frac{1}{\theta_{t}} v^{\prime}\left(\frac{\tilde{y}_{t}^{i}\left(\theta^{t}\right)}{\theta_{t}}\right) .
\end{aligned}
$$

Given the agents' choices, firm $i$ 's profits are $\sum_{t=1}^{T} q^{t} \sum_{\theta^{t}} \pi\left(\theta^{t}\right) \tilde{b}_{t}^{i}\left(\theta^{t}\right)=0$.

\section{Step 2}

We next show that the proposed menus offered at time zero constitute an equilibrium. To do this, we show that no firm wishes to deviate from the proposed equilibrium. Note that since firms $i \in\{1,2\}$ offer the same menus, showing that no firm $i \notin\{1,2\}$ wishes to deviate is analogous to showing that neither $i=1$ or $i=2$ wishes to deviate.

Let $W^{\star}$ be the utility derived by the agent in the proposed equilibrium. Let $\widehat{W}$ be the utility derived by the agent following a deviation of an entrant (that is: accepting a contract offered by an entrant and any additional transfers from the incumbents). Our goal is to show that $W^{\star} \geq \widehat{W}$. At time $t$, let the optimal choice by the agent of type $\theta_{t}$ and previous history $\theta^{t-1}$ within the entrant and incumbent menus be given by $\left(\widehat{b}_{t}\left(\theta^{t-1}, \theta_{t}\right), \widehat{y}_{t}\left(\theta^{t-1}\right)\right)$. Similarly to $(25)$, let: $\widehat{\mathbf{b}}_{t}\left(\theta^{t-1}\right)=$ $\sum_{s=0}^{T-t} q^{s} \sum_{\theta^{s}} \pi\left(\theta^{s}\right) \widehat{b}_{t}\left(\theta^{t-1}, \theta^{s}\right)$ be the expected transfer from time $t$ (included) onwards. Given a history $\theta^{t-1}$, let $\widehat{W}_{t}\left(\widehat{\mathbf{b}}_{t}\left(\theta^{t-1}\right)\right)$ be the utility derived by an agent from time $t$ onwards with the expected transfer to the agent equal to $\widehat{\mathbf{b}}_{t}\left(\theta^{t-1}\right)$. Similarly, let $W_{t}^{\star}\left(\widehat{\mathbf{b}}_{t}\left(\theta^{t-1}\right)\right)$ be the utility derived from choosing contracts with either one of the incumbents assuming that the current resources available at time $t$ are equal to $\widehat{\mathbf{b}}_{t}\left(\theta^{t-1}\right)$. We show that for all $t$ and $\theta^{t-1}$ we have $W_{t}^{\star}\left(\widehat{\mathbf{b}}_{t}\left(\theta^{t-1}\right)\right) \geq \widehat{W}_{t}\left(\widehat{\mathbf{b}}_{t}\left(\theta^{t-1}\right)\right)$. Since at time zero expected profits from the incumbent are zero, we have that $W^{\star}=W_{0}^{\star}(0) \geq \widehat{W}_{0}(0) \geq \widehat{W}$. We prove the result by backward induction. We begin 
at time $T$. Given a history $\theta^{T-1}$, we show that for all $\theta^{T-1}, W_{T}^{\star}\left(\widehat{\mathbf{b}}_{T}\left(\theta^{T-1}\right)\right)>\widehat{W}_{T}\left(\widehat{\mathbf{b}}_{T}\left(\theta^{T-1}\right)\right)$, that is (suppressing notation for previous histories):

$$
\begin{gathered}
\sum_{\theta \in \Theta} \pi(\theta)\left\{u\left(b_{T}^{\star}(\theta)+y_{T}^{\star}(\theta)\right)-v\left(\frac{y_{T}^{\star}(\theta)}{\theta}\right)\right\}> \\
\sum_{\theta \in \Theta} \pi(\theta)\left\{u\left(\widehat{b}_{T}(\theta)+\widehat{y}_{T}(\theta)\right)-v\left(\frac{\widehat{y}_{T}(\theta)}{\theta}\right)\right\} .
\end{gathered}
$$

Note that within the contracts specified in Step 1, it is not possible to have transfers at time $T$ being conditional on $\theta$, so that for all $\theta, b_{T}^{\star}\left(\theta^{T-1}, \theta\right)=\widehat{\mathbf{b}}_{T}\left(\theta^{T-1}\right)$. Transfer conditional on $\theta$ are however a possibility with the entrant. Since agents can choose $\widehat{y}_{T}(\cdot)$ instead of $y_{T}^{\star}(\cdot)$ in $C_{T}^{S}$ this implies:

$$
W_{T}^{\star}\left(\widehat{\mathbf{b}}_{T}\right) \geq \sum_{\theta \in \Theta} \pi(\theta)\left\{u\left(\widehat{\mathbf{b}}_{T}+\widehat{y}_{T}(\theta)\right)-v\left(\frac{\widehat{y}_{T}(\theta)}{\theta}\right)\right\} .
$$

Given the above, a sufficient condition for (C.1) to hold is that:

$$
\sum_{\theta \in \Theta} \pi(\theta)\left\{u\left(\widehat{\mathbf{b}}_{T}+\widehat{y}_{T}(\theta)\right)-v\left(\frac{\widehat{y}_{T}(\theta)}{\theta}\right)\right\}>\sum_{\theta \in \Theta} \pi(\theta)\left\{u\left(\widehat{b}_{T}(\theta)+\widehat{y}_{T}(\theta)\right)-v\left(\frac{\widehat{y}_{T}(\theta)}{\theta}\right)\right\},
$$

which reduces to:

$$
\sum_{\theta \in \Theta} \pi(\theta) u\left(\widehat{\mathbf{b}}_{T}+\widehat{y}_{T}(\theta)\right)>\sum_{\theta \in \Theta} \pi(\theta) u\left(\widehat{b}_{T}(\theta)+\widehat{y}_{T}(\theta)\right) .
$$

Let $c(\theta)=\widehat{\mathbf{b}}_{T}+\widehat{y}_{T}(\theta)$ and $\widehat{c}(\theta)=\widehat{b}_{T}(\theta)+\widehat{y}_{T}(\theta)$. Using similar arguments as in Lemma 3 (with $C_{t}^{S}$ replacing the entrant's contract in the Lemma), we can restrict attention to contracts that imply that if for some $\theta$ and $\theta^{\prime}$ we have $b(\theta) \geq b\left(\theta^{\prime}\right)$ then $y(\theta) \geq y\left(\theta^{\prime}\right)$. This implies that the stochastic process described by $c(\theta)$ second order stochastically dominates the process described by $\widehat{c}(\theta)$. Hence, following Rothschild and Stiglitz (1970), we have that (C.3) holds so that in turn (C.1) holds.

We now show the second step of the inductive assumption. We show that for any history $\theta^{t}$ if an agent receives less utility by choosing contracts with the entrant from time $t+1$ onwards: $\widehat{W}_{t+1}\left(\widehat{\mathbf{b}}_{t+1}\left(\theta^{t}\right)\right)<W_{t+1}^{\star}\left(\widehat{\mathbf{b}}_{t+1}\left(\theta^{t}\right)\right)$, then it will receive less utility from time $t$ onwards:

$$
\widehat{W}_{t}\left(\widehat{\mathbf{b}}_{t}\left(\theta^{t-1}\right)\right)<W_{t}^{\star}\left(\widehat{\mathbf{b}}_{t}\left(\theta^{t-1}\right)\right), \quad \forall \theta^{t-1} .
$$

Given the definition of $\widehat{A}_{t}\left(\theta^{t-1}, \theta_{t}\right)$ in equation (B.3), we can restate the inductive assumption as follows:

$$
\widehat{W}_{t+1}\left(\widehat{\mathbf{b}}_{t+1}\left(\theta^{t}\right)\right)<W_{t+1}^{\star}\left(\frac{1}{q}\left(\widehat{A}_{t}\left(\theta^{t-1}, \theta_{t}\right)-\widehat{b}_{t}\left(\theta^{t-1}, \theta_{t}\right)\right)\right), \quad \forall\left(\theta^{t-1}, \theta_{t}\right) .
$$

Define $x_{t}\left(\theta^{t-1}, \theta_{t}\right)$ as the additional transfer made at $t$ required to make the agent accepting the allocation for type $\theta_{t}$ indifferent between $\widehat{W}_{t+1}$ and $W_{t+1}^{\star}$. Formally, for all $\left(\theta^{t-1}, \theta_{t}\right)$ :

$$
\widehat{W}_{t+1}\left(\widehat{\mathbf{b}}_{t+1}\left(\theta^{t}\right)\right)=W_{t+1}^{\star}\left(\frac{1}{q}\left(\widehat{A}_{t}\left(\theta^{t-1}, \theta_{t}\right)-x_{t}\left(\theta^{t-1}, \theta_{t}\right)-\widehat{b}_{t}\left(\theta^{t-1}, \theta_{t}\right)\right)\right) .
$$

Given the inductive assumption $x_{t}\left(\theta^{t-1}, \theta_{t}\right)>0$, we begin by showing that if for some $\theta^{t-1}$, $\theta_{t}$ and $\theta_{t}^{\prime}$ we can restrict attention to contracts such that if $\widehat{A}_{t}\left(\theta^{t-1}, \theta_{t}\right)-x_{t}\left(\theta^{t-1}, \theta_{t}\right)>$ 
$\widehat{A}_{t}\left(\theta^{t-1}, \theta_{t}^{\prime}\right)-x_{t}\left(\theta^{t-1}, \theta_{t}^{\prime}\right)$ then $\widehat{y}_{t}\left(\theta^{t-1}, \theta_{t}\right)>\widehat{y}_{t}\left(\theta^{t-1}, \theta_{t}^{\prime}\right){ }^{21}$ If that is not the case, so that $\widehat{y}_{t}\left(\theta_{t}\right) \leq \widehat{y}_{t}\left(\theta_{t}^{\prime}\right)$, we show that the entrant will not be able to separate agents of type $\theta_{t}$ and $\theta_{t}^{\prime}$. This is because agents of type $\theta_{t}^{\prime}$ can increase utility by choosing the following: within $C_{t}^{S}$ the amount $\delta_{y}=\widehat{y}_{t}\left(\theta_{t}^{\prime}\right)-\widehat{y}_{t}\left(\theta_{t}\right) \geq 0$; within $C_{t}^{D}$ the amount $\delta_{b}=\widehat{b}_{t}\left(\theta_{t}^{\prime}\right)-\widehat{b}_{t}\left(\theta_{t}\right)$; and the amount $-\delta_{b} / q$ within $C_{t+1}^{D}$; finally within the entrant's menu, the allocation for agents of type $\theta_{t}$. The utility from the deviation is:

$$
\begin{array}{r}
u\left(\widehat{b}_{t}\left(\theta_{t}\right)+\widehat{y}_{t}\left(\theta_{t}^{\prime}\right)+\delta_{b}\right)-v\left(\frac{\widehat{y}_{t}\left(\theta_{t}^{\prime}\right)}{\theta_{t}^{\prime}}\right)+\beta W_{t+1}^{\star}\left(\frac{1}{q}\left(\widehat{A}_{t}\left(\theta_{t}\right)-x_{t}\left(\theta_{t}\right)-\widehat{b}_{t}\left(\theta_{t}\right)-\delta_{b}\right)\right)> \\
u\left(\widehat{b}_{t}\left(\theta_{t}^{\prime}\right)+\widehat{y}_{t}\left(\theta_{t}^{\prime}\right)\right)-v\left(\frac{\widehat{y}_{t}\left(\theta_{t}^{\prime}\right)}{\theta_{t}^{\prime}}\right)+\beta W_{t+1}^{\star}\left(\frac{1}{q}\left(\widehat{A}_{t}\left(\theta_{t}^{\prime}\right)-x_{t}\left(\theta_{t}^{\prime}\right)-\widehat{b}_{t}\left(\theta_{t}^{\prime}\right)\right)\right)= \\
u\left(\widehat{b}_{t}\left(\theta_{t}^{\prime}\right)+\widehat{y}_{t}\left(\theta_{t}^{\prime}\right)\right)-v\left(\frac{\widehat{y}_{t}\left(\theta_{t}^{\prime}\right)}{\theta_{t}^{\prime}}\right)+\beta \widehat{W}_{t+1}\left(\theta_{t}^{\prime}\right),
\end{array}
$$

where the strict inequality follows from $\widehat{A}_{t}\left(\theta_{t}\right)-x_{t}\left(\theta_{t}\right)>\widehat{A}_{t}\left(\theta_{t}^{\prime}\right)-x_{t}\left(\theta_{t}^{\prime}\right)$.

We next show that equation (C.4) holds. As in the case for time $T$, suppose that each agent chooses within an available $C_{t}^{S}$ output as to replicate the output required when accepting the entrant contract. Similarly, suppose that each agent chooses inter-temporal transfers within an available $C_{t}^{D}$ so that the continuation utility is equal to the one received under the entrant contract. Formally:

$$
\begin{aligned}
& W_{t}^{\star}\left(\widehat{\mathbf{b}}_{t}\left(\theta^{t-1}\right)\right) \geq \\
& \sum_{\theta_{t} \in \Theta} \pi\left(\theta_{t}\right) u\left(\widehat{\mathbf{b}}_{t}\left(\theta^{t-1}\right)-\widehat{A}_{t}\left(\theta^{t-1}, \theta_{t}\right)+\widehat{b}_{t}\left(\theta^{t-1}, \theta_{t}\right)+x_{t}\left(\theta^{t-1}, \theta_{t}\right)+\widehat{y}_{t}\left(\theta_{t}\right)\right)- \\
& -v\left(\frac{\widehat{y}_{t}\left(\theta_{t}\right)}{\theta_{t}}\right)+\beta W_{t+1}^{\star}\left(\frac{1}{q}\left(\widehat{A}_{t}\left(\theta^{t-1}, \theta_{t}\right)-x_{t}\left(\theta^{t-1}, \theta_{t}\right)-\widehat{b}_{t}\left(\theta^{t-1}, \theta_{t}\right)\right)\right) .
\end{aligned}
$$

Since $W_{t+1}^{\star}\left(1 / q\left(\widehat{A}_{t}\left(\theta^{t-1}, \theta_{t}\right)-x_{t}\left(\theta^{t-1}, \theta_{t}\right)-\widehat{b}_{t}\left(\theta^{t-1}, \theta\right)\right)\right)=\widehat{W}_{t+1}\left(\widehat{\mathbf{b}}_{t+1}\left(\theta^{t}\right)\right)$, using the above, to show that equation (C.4) holds we need to show that:

$$
\begin{aligned}
& \sum_{\theta_{t} \in \Theta} \pi\left(\theta_{t}\right) u\left(\widehat{\mathbf{b}}_{t}\left(\theta^{t-1}\right)-\widehat{A}_{t}\left(\theta^{t-1}, \theta_{t}\right)+\widehat{b}_{t}\left(\theta^{t-1}, \theta_{t}\right)+x_{t}\left(\theta^{t-1}, \theta_{t}\right)+\widehat{y}_{t}\left(\theta_{t}\right)\right)> \\
& \sum_{\theta_{t} \in \Theta} \pi\left(\theta_{t}\right) u\left(\widehat{b}_{t}\left(\theta^{t-1}, \theta_{t}\right)+\widehat{y}_{t}\left(\theta_{t}\right)\right) .
\end{aligned}
$$

Let $\mathcal{X}_{t}\left(\theta^{t-1}\right)=\sum_{\theta \in \Theta} \pi(\theta) x_{t}\left(\theta^{t-1}, \theta\right)$ and $\zeta\left(\theta^{t-1}, \theta\right)=\widehat{\mathbf{b}}_{t}\left(\theta^{t-1}\right)-\mathcal{X}_{t}\left(\theta^{t-1}\right)-\widehat{A}_{t}\left(\theta^{t-1}, \theta_{t}\right)+$ $x_{t}(\theta)$. By the definition of $A_{t}$ and $\mathcal{X}_{t}, \zeta$ is a mean zero random variable. We then have:

$$
\begin{aligned}
& \sum_{\theta_{t} \in \Theta} \pi\left(\theta_{t}\right) u\left(\widehat{\mathbf{b}}_{t}\left(\theta^{t-1}\right)-\widehat{A}_{t}\left(\theta^{t-1}, \theta_{t}\right)+\widehat{b}_{t}\left(\theta^{t-1}, \theta_{t}\right)+x_{t}\left(\theta^{t-1}, \theta_{t}\right)+\widehat{y}_{t}\left(\theta_{t}\right)\right)= \\
= & \sum_{\theta_{t} \in \Theta} \pi\left(\theta_{t}\right) u\left(\widehat{b}_{t}\left(\theta^{t-1}, \theta_{t}\right)+\widehat{y}_{t}\left(\theta_{t}\right)+\zeta\left(\theta^{t-1}, \theta_{t}\right)+\mathcal{X}_{t}\left(\theta^{t-1}\right)\right)> \\
> & \sum_{\theta_{t} \in \Theta} \pi\left(\theta_{t}\right) u\left(\widehat{b}_{t}\left(\theta^{t-1}, \theta_{t}\right)+\widehat{y}_{t}\left(\theta_{t}\right)\right) .
\end{aligned}
$$

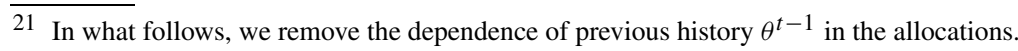


Where the strict inequality follows from the fact that for all $\theta^{t-1}$ we have $\mathcal{X}_{t}\left(\theta^{t-1}\right) \geq 0$ and the fact that $\zeta$ is a zero mean, spread reducing random variable. This is because, as shown earlier, $\widehat{A}_{t}\left(\theta^{t-1}, \theta_{t}\right)-x_{t}\left(\theta^{t-1}, \theta_{t}\right)$ positively co-moves with $\widehat{y}_{t}\left(\theta^{t-1}, \theta_{t}\right)$. Since (C.7) holds, it follows that (C.4) holds. We have shown that $W^{\star} \geq \widehat{W}$. This completes the proof of equilibrium since no firm, nor agent wishes to deviate from the proposed equilibrium.

\section{C.1. Proof of Proposition 4}

Suppose the result does not hold, so that $W^{\star} \neq \bar{W}$. In the body of the paper, the case $W^{\star}<\bar{W}$ was ruled out. We consider the remaining case $\bar{W}<W^{\star}$. The strategy is similar to Cole and Kocherlakota (2001): we consider an alternative infinite horizon environment that can bound the time zero payoff of our benchmark environment. Suppose the time horizon is infinite but assume that from time $\widehat{T}>1$ onwards the environment features no uncertainty. In particular, each agent receives the highest shock $\bar{\theta}=\max \{\theta \in \Theta\}$ from time $\widehat{T}$ onwards. We refer to the environment just described as the $\widehat{T}$-truncated environment. Denote by $\widehat{W}(\widehat{T})$ the ex ante, time zero payoff of the agent in this environment. We have that for all $\widehat{T}$-truncated environments, $\widehat{W}(\widehat{T}) \geq W^{\star}$. Consider next the self-insurance benchmark within the $\widehat{T}$-truncated environment (that is a self-insurance environment with no uncertainty after $\widehat{T}$ ). Denote the time zero payoff for the self-insurance case as $\bar{W}(\widehat{T})$. We have that:

$$
\lim _{\widehat{T} \rightarrow \infty} \bar{W}(\widehat{T})=\bar{W}
$$

In the following Lemma, we establish the relationship between the candidate equilibrium and the self-insurance environment in the $\widehat{T}$-truncated environment.

Lemma 5. For all $\widehat{T}$, we have that $\widehat{W}(\widehat{T})=\bar{W}(\widehat{T})$.

Proof. As a first step, we show that each $\widehat{T}$-truncated environment features no insurance (for all $\theta^{t-1}, \theta$ and $\theta^{\prime}$ we have $\left.A_{t}\left(\theta^{t-1}, \theta\right)=A_{t}\left(\theta^{t-1}, \theta^{\prime}\right)\right)$ and no intra-temporal distortions (condition (20) is satisfied). The key observation is that for all $\widehat{T}$, in the $\widehat{T}$-truncated environment, Lemma 1 , Lemma 2, Lemma 3, and Lemma 4 all apply. Let $\mathbf{b}_{\widehat{T}}\left(\theta^{\widehat{T}-1}\right)$ denote the present discounted value of transfers that the agent will receive from time $\widehat{T}$ onwards. Following similar arguments as in the proof of Proposition 1, we then have that continuation utility from time $\widehat{T}$ included onwards can be described with a function $S\left(\mathbf{b}_{\widehat{T}}\left(\theta^{T}-1\right)\right)$ with $S$ strictly increasing and concave. With this step completed, the remaining part of the proof follows exactly the proof of Proposition 1.

Recall that from the contradicting assumption we had $W^{\star}>\bar{W}$. To complete the proof of Proposition 4, we finally have that:

$$
\bar{W}=\lim _{\widehat{T} \rightarrow \infty} \widehat{W}(\widehat{T}) \geq W^{\star}>\bar{W}
$$

where the first equality follows from Lemma 5 and equation (C.8). We thus reach a contradiction. This completes the proof of Proposition 4.

\section{References}

Abraham, A., Koehne, S., Pavoni, N., 2011. On the first-order approach in principal-agent models with hidden borrowing and lending. J. Econ. Theory 146 (4), 1331-1361. 
Abraham, A., Pavoni, N., 2005. The efficient allocation of consumption under moral hazard and hidden access to the credit market. J. Eur. Econ. Assoc. 3 (2-3), 370-381.

Abraham, A., Pavoni, N., 2008. Efficient allocations with moral hazard and hidden borrowing and lending: a recursive formulation. Rev. Econ. Dyn. 11 (4), 781-803.

Aguiar, M., Hurst, E., 2005. Consumption versus expenditure. J. Polit. Econ. 113 (5), 919-948.

Aiyagari, S.R., 1994. Uninsured idiosyncratic risk and aggregate saving. Q. J. Econ. 109 (3), 659-684.

Albanesi, S., 2008. Social insurance. In: Durlauf, S.N., Blume, L.E. (Eds.), The New Palgrave Dictionary of Economics. Palgrave Macmillan.

Albanesi, S., Sleet, C., 2006. Dynamic optimal taxation with private information. Rev. Econ. Stud. 73 (1), 1-30.

Ales, L., Maziero, P., 2008. Accounting for private information. Minneapolis Fed working paper 663.

Ales, L., Maziero, P., 2013. Adverse selection and non-exclusive contracts. Carnegie Mellon University. Unpublished Manuscript.

Ales, L., Sleet, C., 2014. Revision proofness. J. Econ. Theory 152, 324-355.

Allen, F., 1985. Repeated principal-agent relationships with lending and borrowing. Econ. Lett. 17 (1-2), 27-31.

Armstrong, M., Vickers, J., 2010. Competitive non-linear pricing and bundling. Rev. Econ. Stud. 77 (1), 30-60.

Arnott, R., Stiglitz, J., 1991. Equilibrium in competitive insurance markets with moral hazard. NBER working paper 3588 .

Atkeson, A., Lucas, R., 1992. On efficient distribution with private information. Rev. Econ. Stud. 59 (3), 427-453.

Attar, A., Mariotti, T., Salanié, F., 2011. Nonexclusive competition in the market for lemons. Econometrica 79 (6), 1869-1918.

Attar, A., Mariotti, T., Salanié, F., 2014. Non-exclusive competition under adverse selection. Theor. Econ. 9 (1).

Biais, B., Martimort, D., Rochet, J., 2000. Competing mechanisms in a common value environment. Econometrica 68 (4), 799-837.

Bisin, A., Guaitoli, D., 2004. Moral hazard and non-exclusive contracts. Rand J. Econ. 35 (2), 306-328.

Chamberlain, G., Wilson, C.A., 2000. Optimal intertemporal consumption under uncertainty. Rev. Econ. Dyn. 3 (3), 365-395.

Cole, H., Kocherlakota, N., 2001. Efficient allocations with hidden income and hidden storage. Rev. Econ. Stud. 68 (3), 523-542.

Doob, J.-L., 1953. Stochastic Processes.

Epstein, L., Peters, M., 1999. A revelation principle for competing mechanisms. J. Econ. Theory 88 (1), 119-160.

Farhi, E., Golosov, M., Tsyvinski, A., 2009. A theory of liquidity and regulation of financial intermediation. Rev. Econ. Stud. 76 (3), 973-992.

Farhi, E., Werning, I., 2008. Optimal savings distortions with recursive preferences. J. Monet. Econ. 55 (1), 21-42.

Farhi, E., Werning, I., 2013. Insurance and taxation over the life cycle. Rev. Econ. Stud. 80 (2), 596-635.

Fukushima, K., 2010. Quantifying the welfare gains from flexible dynamic income tax systems. University of Minnesota. Manuscript.

Garrett, D., Pavan, A., 2013. Dynamic managerial compensation: on the optimality of seniority based schemes.

Golosov, M., Kocherlakota, N., Tsyvinski, A., 2003. Optimal indirect and capital taxation. Rev. Econ. Stud. 70 (3), $569-587$.

Golosov, M., Troshkin, M., Tsyvinski, A., 2016. Redistribution and social insurance. Am. Econ. Rev. 106 (2), 359-386.

Golosov, M., Tsyvinski, A., 2007. Optimal taxation with endogenous insurance markets. Q. J. Econ. 122 (2), 487-534.

Golosov, M., Tsyvinski, A., Werning, I., 2006. New dynamic public finance: a user's guide. NBER Macroecon. Annu. 21, $317-363$.

Guesnerie, R., 1998. A Contribution to the Pure Theory of Taxation. Econom. Soc. Monogr., vol. 25. Cambridge University Press.

Hammond, P., 1987. Markets as constraints: multilateral incentive compatibility in continuum economies. Rev. Econ. Stud. 54, 399-412.

Huggett, M., 1993. The risk-free rate in heterogeneous-agent incomplete-insurance economies. J. Econ. Dyn. Control 17 (5), 953-969.

Kaplan, G., Violante, G.L., 2010. How much consumption insurance beyond self-insurance? Am. Econ. J. Macroecon., 53-87.

Kocherlakota, N., 2010. The New Dynamic Public Finance. Princeton Univ Pr.

Kocherlakota, N.R., 1996. Reconsideration-proofness: a refinement for infinite horizon time inconsistency. Games Econ. Behav. 15 (1), 33-54.

Martimort, D., Stole, L., 2002. The revelation and delegation principles in common agency games. Econometrica 70 (4), $1659-1673$. 
Milgrom, P., Segal, I., 2002. Envelope theorems for arbitrary choice sets. Econometrica 70 (2), 583-601.

Mirrlees, J., 1971. An exploration in the theory of optimum income taxation. Rev. Econ. Stud. 38 (114), 175-208.

Myerson, R., 1982. Optimal coordination mechanisms in principal-agent problems. J. Math. Econ. 11, 67-81.

Pavan, A., Calzolari, G., 2010. Truthful revelation mechanisms for simultaneous common agency games. Am. Econ. J. Microecon. 2 (2), 132-190.

Paxson, C., Sicherman, N., 1994. The dynamics of dual-job holding and job mobility. NBER working paper W4968.

Peters, M., 2001. Common agency and the revelation principle. Econometrica 69 (5), 1349-1372.

Prescott, E., Townsend, R., 1984. Pareto optima and competitive equilibria with adverse selection and moral hazard. Econometrica 52 (1), 21-45.

Rochet, J.-C., 1986. Le Contrôle des Équations aux Dérivées Partielles Issues de la Théorie des Incitations. Ph.D. thesis. Rogerson, W., 1985. Repeated moral hazard. Econometrica 53 (1), 69-76.

Rothschild, M., Stiglitz, J.E., 1970. Increasing risk: I. A definition. J. Econ. Theory 2 (3), 225-243.

Salanié, B., 2003. The Economics of Taxation. MIT Press.

Stiglitz, J.E., 1982. Self-selection and Pareto efficient taxation. J. Public Econ. 17 (2), 213-240.

Thomas, J., Worrall, T., 1990. Income fluctuation and asymmetric information: an example of a repeated principal-agent problem. J. Econ. Theory 51 (2), 367-390.

Weinzierl, M., 2011. The surprising power of age-dependent taxes. Rev. Econ. Stud. 78 (4), 1490-1518. 